\title{
Performance Demonstration Program Plan for Nondestructive Assay for the TRU Waste Characterization Program
}

\author{
CAO-94-1045 \\ Revision 1 \\ U.S. Department of Energy \\ Carlsbad Area Office
}

May 1997 


\section{U.S. Department of Energy}

Carlsbad Area Office National TRU Program

\section{Performance Demonstration Program Plan for Nondestructive Assay for the TRU Waste Characterization Program \\ CAO-94-1045 \\ Revision 1}

May 1997
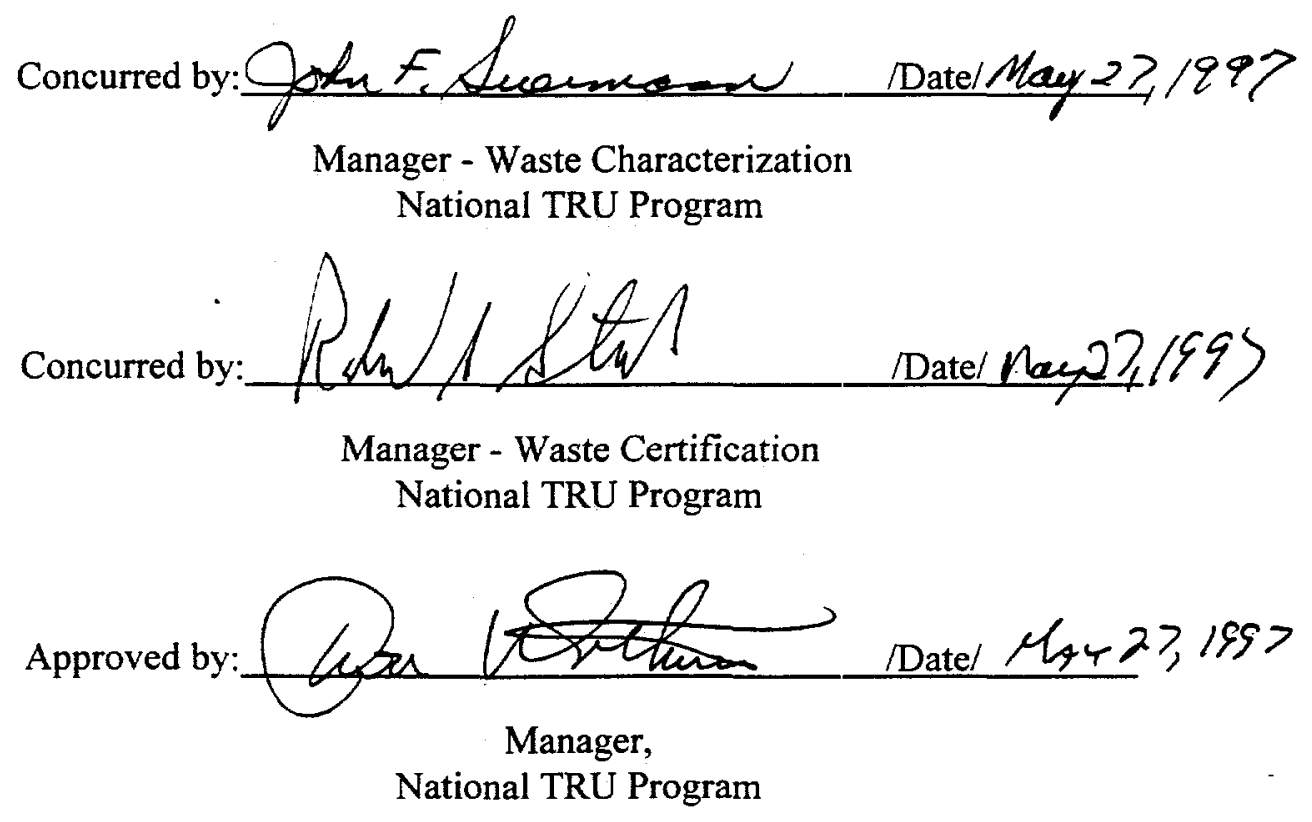


\section{DISCLAIMER}

This report was prepared as an account of work sponsored by an agency of the United States Government. Neither the United States Government nor any agency thereof, nor any of their employees, make any warranty, express or implied, or assumes any legal liability or responsibility for the accuracy, completeness, or usefulness of any information, apparatus, product, or process disclosed, or represents that its use would not infringe privately owned rights. Reference herein to any specific commercial product, process, or service by trade name, trademark, manufacturer, or otherwise does not necessarily constitute or imply its endorsement, recommendation, or favoring by the United States Government or any agency thereof. The views and opinions of authors expressed herein do not necessarily state or reflect those of the United States Government or any agency thereof. 


\section{DISCLAIMER}

Portions of this document may be illegible in electronic image products. Images are produced from the best available original document. 


\section{CONTENTS}

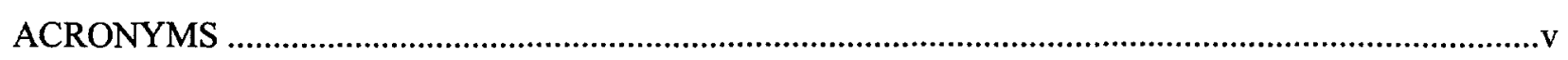

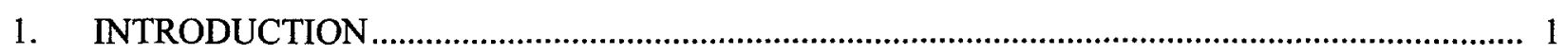

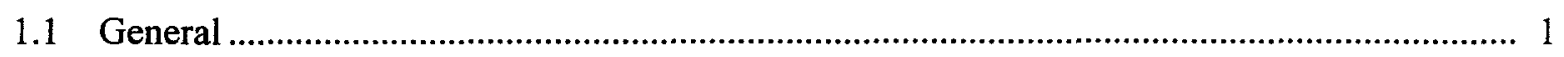

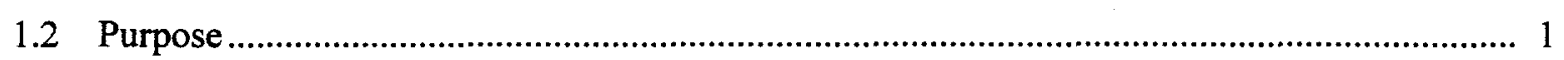

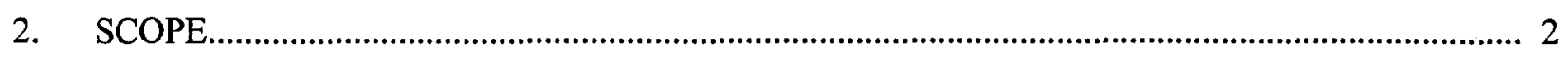

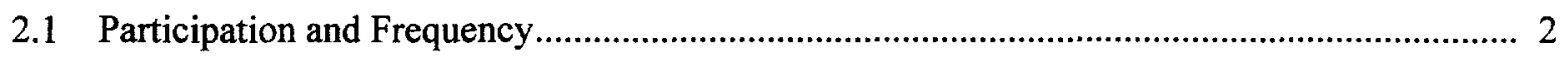

2.2 Isotopes, Activities, and Matrices ............................................................................ 2

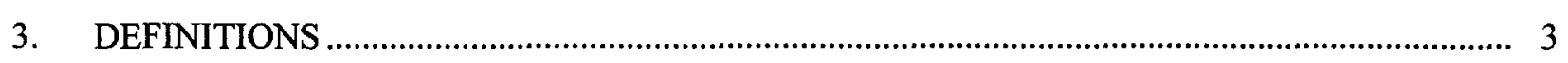

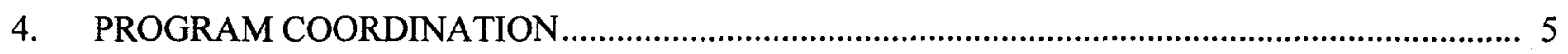

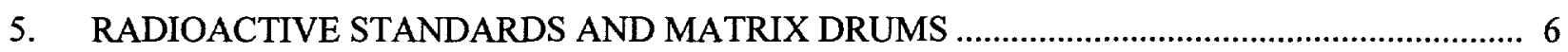

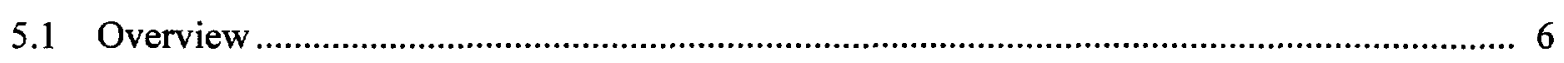

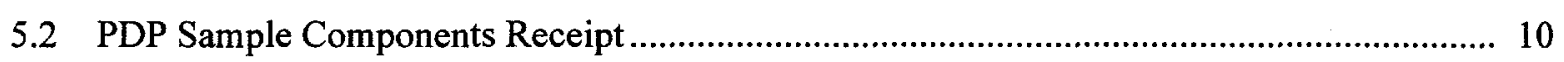

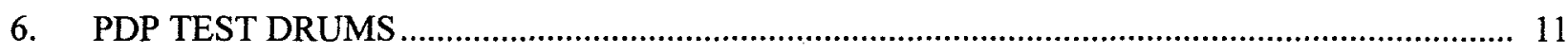

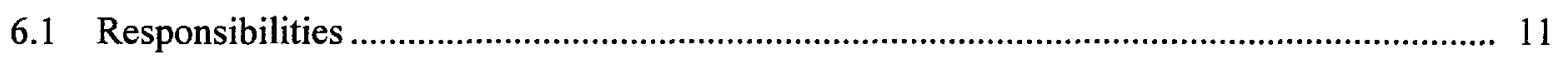

6.2 Instructions for PDP Sample Preparation .............................................................. 11

7. ANALYTICAL AND DATA REPORTING REQUIREMENTS ......................................... 13

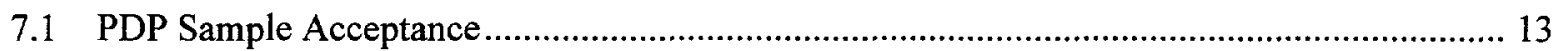

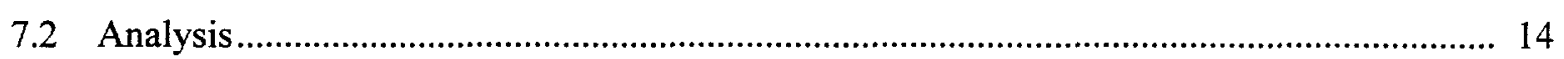

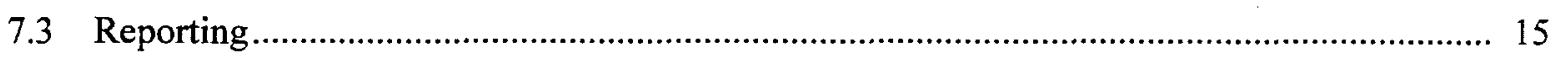

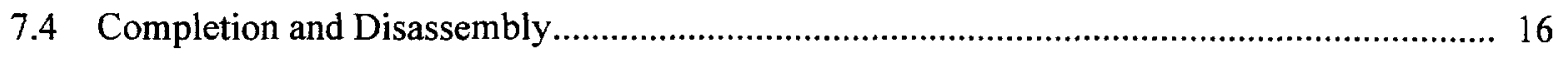

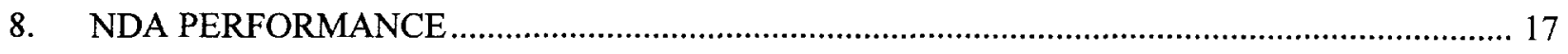

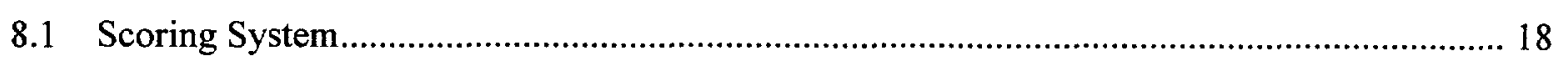

8.1.1 Bias of Quantitation of Simulated TRU Wastes .................................................... 19

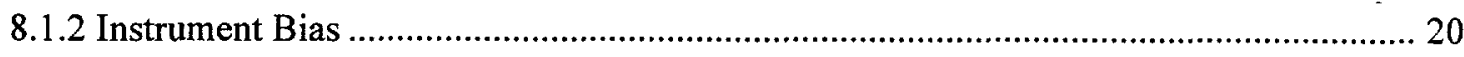

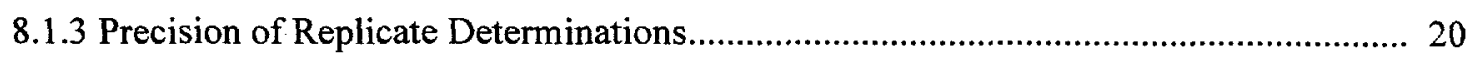




\section{ACRONYMS}

$\begin{array}{ll}\text { BIR } & \text { Baseline Inventory Report } \\ \text { CAO } & \text { Carlsbad Area Office } \\ \text { DOE } & \text { United States Department of Energy } \\ \text { NDA } & \text { Nondestructive Assay } \\ \text { NIST } & \text { National Institute of Standards and Technology } \\ \text { PA } & \text { Performance Assessment } \\ \text { PDP } & \text { Performance Demonstration Program } \\ \text { QAO } & \text { Quality Assurance Objective } \\ \text { QAPP } & \text { Quality Assurance Program Plan } \\ \text { SNM } & \text { Special Nuclear Material } \\ \text { SPT } & \text { Sample Preparation Team } \\ \text { TID } & \text { Tamper Indicating Device } \\ \text { TRU } & \text { Transuranic } \\ \text { WIPP } & \text { Waste Isolation Pilot Plant } \\ \text { WIPP WAC } & \text { WIPP Waste Acceptance Criteria } \\ \text { VTSR } & \text { Validated Time Of Sample Receipt } \\ & \end{array}$




\section{Performance Demonstration Program Plan for Nondestructive Assay for the TRU Waste Characterization Program}

\section{INTRODUCTION}

\subsection{General}

The Performance Demonstration Program (PDP) for Nondestructive Assay (NDA) consists of a series of tests conducted on a regular frequency to evaluate the capability for nondestructive assay of transuranic (TRU) waste throughout the Department of Energy (DOE) complex. Each test is termed a PDP cycle. These evaluation cycles provide an objective measure of the reliability of measurements performed with TRU waste characterization systems.

Measurement facility performance will be demonstrated by the successful analysis of blind audit samples according to the criteria set by this Program Plan. Intercomparison between measurement groups of the DOE complex will be achieved by comparing the results of measurements on similar or identical blind samples reported by the different measurement facilities. Blind audit samples (hereinafter referred to as PDP samples) will be used as an independent means to assess the performance of measurement groups regarding compliance with established Quality Assurance Objectives (QAOs). As defined for this program, a PDP sample consists of a 55-gallon matrix drum emplaced with radioactive standards and fabricated matrix inserts. These PDP sample components, once manufactured, will be secured and stored at each participating measurement facility designated and authorized by Carlsbad Area Office (CAO) under secure conditions to protect them from loss, tampering, or accidental damage.

\subsection{Purpose}

The Performance Demonstration Programs (PDPs) are designed to help ensure compliance with the QAOs identified in the Transuranic Waste Characterization Quality Assurance Program Plan (QAPP) (DOE,1996a) for the Waste Isolation Pilot Plant (WIPP). The PDPs are intended for use by the CAO as part of the assessment and approval process for the measurement facilities supplying services for the character-ization of WIPP TRU waste. The other two parts of this approval process include the evaluation of method performance data submitted by the measurement facility and the performance of quality assurance audits. The PDP may also be used by the CAO in qualifying facilities that propose to supply additional analytical services required for other than waste characterization, such as support of site operations.

Each PDP is defined in its respective PDP Plan which describes the detailed elements that constitute the program, including the nature of the test materials and the analyses required. The PDP Plan also identifies the criteria that will be used for the evaluation of measurement facility performance and the responsibilities of the program participants including, the Program Coordinator, third party contractors producing standards and other material, Sample Preparation Team (SPT), and the individual testing facilities. The CAO will ensure the implementation of each plan by designating a Program Coordinator and by providing technical oversight and coordination for the program. In addition to the PDP described in the present document, two other PDPs are active. These are described in their respective PDP Plans, the Performance Demonstration Program Plan for Analysis of Simulated Headspace Gases (DOE, 1995) and the Performance Demonstration Program Plan for RCRA Constituent Analysis of Solidified Wastes (DOE, 1996b). 
Isotopic activities in the SPT-prepared PDP samples will encompass the range of concentrations anticipated in actual waste characterization. The removable PDP sample standards will address alpha activity ranges relative to WIPP WAC limits, QAPP QAOs, and/or NDA. method detection limits. Manufactured matrices will simulate expected waste matrix conditions and provide acceptable consistency in the sample preparation process at each measurement facility. Analyses required by the WIPP to demonstrate compliance with various regulatory requirements and included in the PDP may only be performed by measurement facilities that have demonstrated acceptable performance in the PDP. These analyses are referred to as WIPP analyses, and the wastes on which they are performed are referred to as WIPP wastes in this document.

\section{SCOPE}

\subsection{Participation and Frequency}

The CAO reserves the right to modify the testing frequency of this program based on programmatic, budgetary, and other DOE needs. Acceptable performance must be demonstrated by all participating measurement facilities on a semiannual basis. Single blind samples will be prepared by the SPT twice during a calendar year at 6-month ( \pm 1 month) intervals. The criteria for acceptable performance are given in Section 8 of this Program Plan. The PDP samples must be analyzed using the methods the measurement facility anticipates using for the analysis of WIPP wastes. These methods must have been developed and approved within the specifications of the QAPP. Only the methods actually used in the PDP will be considered acceptable to support the analysis of WIPP wastes. The data generated as a result of the performance demonstration will indicate the appropriateness of the method used, as well as the performance of the measurement facility.

The sites that intend to ship TRU waste to the WIPP facility will participate in the PDP. Satisfactory performance of PDP measurements is a necessary but not a sufficient condition for certification to ship TRU waste to WIPP. Additional requirements for method performance demonstrations and other quality assurance practices are contained in Chapter 9 of the QAPP.

\subsection{Isotopes, Activities, and Matrices}

The radioassay portions of the current versions of the PDP and the QAPP define quality assurance objectives and measurement requirements only for waste characterization of alpha-emitting isotopes associated with weapons grade plutonium. As the Performance Assessment (PA) for the WIPP facility is completed, it is anticipated that additional characterization information will be required. The QAOs for this additional characterization information will be incorporated in the QAPP and will then be reflected in the PDP. Subsequent cycles of the PDP will likely contain measurement requirements and tests for demonstrating compliance with these additional characterization requirements.

The isotopes to be analyzed under this Program Plan are presented in Table 1. Additional components may be added to future revisions of the PDP, requiring Table 1 to be expanded to include additional isotopics and classifications. Future selected isotopes will have been identified in documentation as

1. Critical to performance assessment for the WIPP, or

2. Having regulatory concerns referenced in 40 CFR 191 and/or 40 CFR 194.

In addition to the radioactive standard support and access structure, the 55-gallon drums may also contain manufactured matrix inserts. These manufactured matrices will be designed to simulate the 
interfering effects of real waste forms. A broad spectrum of TRU waste forms are distributed across the DOE facilities. It is intended that the PDP tests will eventually include sufficient different simulated waste forms to test the full range of measurement interferences expected to be encountered in assaying these waste forms. The design of the matrix inserts will be developed from the 11 specific waste forms defined in the Transuranic Waste Baseline Inventory Report (BIR) (DOE, 1996c) for the Waste Isolation Pilot Plant. Initially the PDP utilized sample 55-gallon drums that contained either no matrix material or relatively noninterfering material. As the program progresses, individual cycles will include additional matrix drums intended to test all of the potential interference effects that can be tested under the PDP program.

Additional details of the implementation program are described in subsequent sections of this document.

Table 1. PDP radioisotopes of interest

\section{Isotope}
1. $238 \mathrm{Pu}$
2. $239 \mathrm{Pu}$
3. $240 \mathrm{Pu}$
4. $241 \mathrm{Am}$

\section{DEFINITIONS}

Accuracy

Assay Coordinator

Benign Matrix

Bias

Instrument Bias
The closeness of measured value to the true value or to an accepted reference or standard value. Accuracy is often expressed as the percent recovery $(\% \mathrm{R})$.

Facility point-of-contact responsible for accepting PDP samples and ensuring chain of custody protocols are followed.

Material used to manufacture a drum insert that is uniform in distribution and possesses an elemental composition and density which is considered nominally noninterfering with respect to NDA measurement techniques.

The systematic error component of the total uncertainty, that is, a constant positive or negative deviation of the method average from the correct value or an accepted reference value under specific measurement conditions.

The bias of a particular instrument (or measurement system) under essentially ideal conditions, that is, when all sample specific or matrix effects have been reduced to their practical minima. In this program the instrument bias will be approximated by the accuracy of the measurement for samples with the zero matrix or a benign matrix. 
Matrix Drum

Nondestructive Assay

(NDA)

PDP Sample

PDP Standard

PDP Standards

Configuration Attestant

PDP Standards

Custodian

Precision

|

Program Coordinator

Sample Preparation

Procedure

Sample Preparation

Team (SPT)
Department of Transportation, Specification 17C (UN identification code UN1A2/X), 208-L (55-gailon) steel drum acquired and serial numbered for the PDP, including a designed and manufactured drum insert that will simulate an expected waste matrix condition. A zero matrix drum is one containing only the supports for insertable standards.

A technique that allows an item to be assayed without altering its physical or chemical form.

A blind sample prepared and sealed by the SPT for subsequent analysis by a measurement facility for qualification under the PDP. The PDP sample is composed of a 55-gallon matrix drum and insertable PDP standards. Matrix and source characteristics will representatively span nominal waste characteristics to include, but not be limited to, isotopics, plutonium concentration, $(\alpha, n)$ reactions, fission product contamination, interfering matrices, and source distribution.

A radioactive source specifically prepared or acquired and certified for the PDP.

A member of the two-man SPT responsible for verifying the proper emplacement of PDP sample standards and performing sample security-related procedures.

The lead member of the SPT responsible for coordination of on-site PDP sample preparations activities.

A measure of the mutual agreement among individual measurements of the identical PDP sample under fixed conditions; expressed as the standard deviation.

A CAO-designated organization that administers and coordinates PDP functions, such as PDP sample component preparation, SPT oversight, scheduling, scoring, and report summary generation.

A procedure generated by the Program Coordinator for each PDP cycle. This procedure provides the SPT instructions on PDP standard placement and matrix identification within the sample drum.

A two-person team, consisting of a PDP Standards Custodian and PDP Standards Configuration Attestant, that prepares and certifies measurement facility PDP samples. The SPT is responsible for ensuring that each PDP sample is prepared according to the PDP sample preparation procedure. In addition, the SPT will ensure proper disassembly and return to storage of all PDP sample components after analysis by the measurement facility. The SPT will be designated by the site and approved by the Program Coordinator. 
Total Accuracy

1

Total Uncertainty

Zero Matrix

The closeness of the mean results obtained from a measurement system to the known or accepted reference or standard values. In this program Total Accuracy is estimated from the measurement results for PDP samples that include sources of variance in addition to those measured in the zero and noninterfering matrix drums, such as variable matrices, isotopic compositions, spatial distributions, contaminating radionuclides, and other interfering effects. It is used to estimate bias for the interfering matrices.

The total measurement error from all sources of variance, including the precision, the instrument bias, and interference effects such as variable matrices, isotopic compositions, spatial distributions, contaminating radionuclides, and other interfering effects.

Specifies a matrix drum that contains only the supports for insertable standards.

\section{PROGRAM COORDINATION}

The reviewing and approving authority for the PDP is the CAO. The CAO will use the PDP plan to assess, evaluate, and approve DOE facilities (including owned or contracted mobile systems, if applicable) for waste measurement and characterization before the waste is shipped to the WIPP facility. The PDP is only one component of an overall evaluation regime maintained by the CAO.

The CAO will be responsible for ensuring the PDP is conducted on a semiannual basis. A CAO-designated organization shall function as the PDP Coordinator and technical advisor to CAO. For the NDA PDP, the Program Coordinator will:

1. Ensure preparation, control, and distribution of PDP standards and matrix drums.

2. Distribute PDP cycle schedules to facility participants.

3. Confirm the impending initiation of a PDP cycle at least 2 weeks prior to the planned start date.

4. Develop ongoing procedures for PDP sample preparation for standards emplacement and removal, on-site PDP sample certification, and sample drum sealing.

5. Provide training for the on-site Sample Preparation Teams.

6. Receive, review, and compile the analytical data.

7. Report performance data as specified within this document.

The Program Coordinator will provide independent technical oversight and coordination of the demonstration program to qualify participating measurement facilities. The Program Coordinator will maintain a controlled list of the facilities participating in the semi-annual testing program. Measurement facilities required to participate in the PDP will be designated by the CAO. Facilities which are not required to participate but which desire to do so may petition the CAO to be permitted to participate in the PDP. Participation by measurement facilities not actively engaged in characterization of TRU wastes for WIPP-related programs will be at the discretion of the CAO. 
Each participating facility will be required to provide the Program Coordinator with the name, telephone number, fax number, and address of the contact persons responsible for administrative communications for the PDP. Each participating facility will also be required to provide an address suitable for delivery by freight and package delivery service for the matrix drums and the PDP standards.

\section{RADIOACTIVE STANDARDS AND MATRIX DRUMS}

\subsection{Overview}

The Program Coordinator shall ensure preparation and delivery of PDP standards. A PDP standard is defined as a radioactive source specifically designed, prepared (or acquired), and certified for the PDP. PDP standards will be obtained from suppliers who maintain measurement systems traceable to the National Institute of Standards and Technology (NIST). Most standards used in the NDA PDP will be manufactured specifically for the program. However, certified sources from existing programs and commercial sources may be used if the specifications meet a specific program need.

The number of standards and the amount of special nuclear material (SNM) inserted in each matrix drum will be selected from a larger inventory of PDP standards at each site. The subset selected for each drum will be chosen so as to prevent inference of the contained material by the measurement facility assay team. As the PDP progresses, additional PDP standards will be added to the inventory that present more difficult measurement parameters. Also, different types of PDP standards may be used, such as americium-lithium sources, combined with the PDP standards to artificially alter the radiation signature and increase the measurement complexity. The final inventory is currently planned to consist of approximately 30 standards. The CAO reserves the right to modify the projected inventory based on programmatic, budgetary, and other DOE constraints. The types of radioactive materials in the inventory is projected to include at least those types listed in Table 2.

Table 2. Types of radioactive standards in final PDP inventory

\section{Type of Activity}

1. Weapons Grade Plutonium

2. Heat Source Plutonium

3. Highly Enriched Uranium

4. Enhanced $\mathrm{Am} / \mathrm{Pu}$ Ratio (relative to initial values in weapons grade plutonium)

5. Increased particle size (relative to initial distribution in type number 1)

The Program Coordinator shall provide the PDP standard supplier with specifications required for the manufacture of PDP standards, including isotopes of interest, activities, acceptable chemical and physical forms, and geometries for the source material and standard container. Final isotopic activities of 
the PDP standards are left to the discretion of the Program Coordinator. The Program Coordinator will ensure that PDP standards, when used in combination, will encompass the range of material anticipated in actual WIPP waste and defined in the BIR. Identified ranges to which the QAOs apply for (208-L) 55gallon standard drum activities under this Program Plan are listed in Table 3. See Section 8 and Appendix A for an explanation of the statistical basis for the differences between the QAOs in the QAPP and the criteria for the measured precision data. The geometry of the PDP standards will be compatible with PDP matrix drum insert fixtures to allow secure and accurate placement within the 55-gallon matrix drum. Refer to Appendix B for detailed specifications for PDP radioactive standards.

Table 3. PDP sample activities and associated quality assurance objectives.

\begin{tabular}{|c|c|c|c|c|c|c|}
\hline \multirow[b]{2}{*}{$\begin{array}{l}\text { Activity } \\
\text { range }\end{array}$} & \multirow[b]{2}{*}{$\begin{array}{c}\text { Range of } \\
\text { waste activity } \\
\text { in } \alpha \text {-Curies }\end{array}$} & \multirow[b]{2}{*}{$\begin{array}{c}\text { QAO for } \\
\text { precision }^{b} \\
(\% \text { RSD) }\end{array}$} & \multicolumn{2}{|c|}{$\begin{array}{l}\text { Maximum Measured } \\
\text { Precision }^{\mathrm{c}}\end{array}$} & \multicolumn{2}{|c|}{$\begin{array}{c}\text { Bias }^{\mathrm{d}} \\
\left(\% \mathrm{R}_{\mathrm{L}} \text { and } \% \mathrm{R}_{\mathrm{H}} \text { in Equation } 3\right)\end{array}$} \\
\hline & & & $\begin{array}{c}\text { Noninterfering } \\
\text { matrix } \\
(\% \text { RSD })\end{array}$ & $\begin{array}{c}\text { Interfering } \\
\text { matrix } \\
(\% \mathrm{RSD})\end{array}$ & $\begin{array}{c}\text { Noninterfering } \\
\text { matrix } \\
(\% \mathrm{R})\end{array}$ & $\begin{array}{c}\text { Interfering } \\
\text { matrix } \\
(\% \mathrm{R})\end{array}$ \\
\hline Low & $>0$ to 0.02 & $20 \%$ & $14 \%$ & $16 \%$ & $\begin{array}{l}\text { Low: } 75 \% \\
\text { High: } 125 \%\end{array}$ & $\begin{array}{l}\text { Low: } 40 \% \\
\text { High: } 175 \%\end{array}$ \\
\hline Mid-Low & $>0.02$ to 0.2 & $15 \%$ & $10.5 \%$ & $12 \%$ & $\begin{array}{l}\text { Low: } 50 \% \\
\text { High: } 150 \%\end{array}$ & $\begin{array}{l}\text { Low: } 30 \% \\
\text { High: } 200 \%\end{array}$ \\
\hline Mid-High & $>0.2$ to 2.0 & $10 \%$ & $7 \%$ & $12 \%$ & $\begin{array}{l}\text { Low: } 50 \% \\
\text { High: } 150 \%\end{array}$ & $\begin{array}{l}\text { Low: } 30 \% \\
\text { High: } 200 \%\end{array}$ \\
\hline High & $>2.0$ & $5 \%$ & $3.5 \%$ & $6 \%$ & $\begin{array}{l}\text { Low: } 75 \% \\
\text { High: } 125 \%\end{array}$ & $\begin{array}{l}\text { Low: } 50 \% \\
\text { High: } 150 \%\end{array}$ \\
\hline
\end{tabular}

a. Applicable range of TRU activity in a 208-L (55-gallon) drum to which the QAOs apply; units are Curies of alphaemitting TRU isotopes with half-lives greater than 20 years.

b. Limits in QAPP for one relative standard deviation based on fifteen replicates, $s / \overline{\mathrm{X}}$, expressed as a percent.

c. Measured precisions that must be met to satisfy the same precision criteria as the QAPP QAOs, except based on six replicates. The values are one relative standard deviation referenced to the known (or accepted) value for the test, not to the mean of the measurements, $s / \mu$.

d. Limits on the two-sided $95 \%$ confidence bound for the ratio of the mean of the measured values to the known (or accepted) value, expressed as a percent. 
The Program Coordinator is also responsible for specifying and procuring a series of matrix drums for use in the PDP. A matrix drum is a standard 208-L (55-gallon) waste drum acquired and serial numbered for the PDP, including a designed and manufactured drum insert simulating a nominal waste matrix configuration. One of the PDP drums is a zero matrix drum. The zero matrix drum contains only the fixtures necessary to reproducibly and reliably position the insertable standards. Early in the program there was an attempt to use a second noninterfering matrix drum. This noninterfering matrix drum would have contained a uniformly distributed matrix material (benign matrix) that minimized the use of high density/high $Z$ and/or neutron absorbing or moderating elements, or any other materials possessing characteristics that complicate the analysis of data obtained from existing NDA techniques. It was not possible to design a matrix drum that contained a homogenous material of appreciable mass and still met the criterion of being substantially noninterfering for all NDA methods presently in use within the system. The proposed noninterfering drum has been withdrawn from the program and the empty drum fills the role of noninterfering case.

The other matrix drums in the PDP are representative of real wastes and include materials that exhibit interfering characteristics. To determine which waste matrices would be most appropriate for inclusion in the program, eleven candidate waste forms were reviewed in detail. These waste forms are listed in Table 4 and are based on the Waste Matrix Code Groups presented in the BIR. Interest in the waste forms was limited to two criteria. First, what characteristics does the waste form have that present an interference condition for one or more NDA methods? Second, can this characteristic be simulated in a controlled condition by the design of an simulated waste matrix drum? Some of the acknowledged interference conditions could not be tested by varying the waste matrix. For example, the high $(\alpha, n)$ reaction rate of salt wastes is more properly tested by varying conditions in the source, not by altering the waste matrix. After eliminating the interference conditions that could not be tested by varying the matrix, there was found to be substantial overlap among the waste forms in terms of the interference phenomena exhibited. The objectives of the PDP can be satisfied by testing an assay system's ability to handle the types of interference expected. It is, therefore, not necessary to test each of the waste forms individually if all of the types of interference can be tested in a subset of waste types. It was determined that all of the principal interference mechanisms could be tested using a subset of only six waste forms simulated in PDP matrix drums. The expected final inventory of matrix drums is given in Table 5. Sequential PDP cycles will measure composite errors in progressively more difficult configurations that include interfering effects, such as interfering matrices and fission product contaminants. Although only six different waste matrix drums will be used in the routine PDP tests, this vill be sufficient to test all of the significant interference mechanisms exhibited in all 11 of the waste forms listed in the BIR. It is understood that some waste forms are specific to certain sites. Therefore, the PDP may conduct tests specifically for particular sites, requiring special procurement of PDP sample components by the Program Coordinator.

Refer to Appendix $\mathrm{C}$ for detailed specifications on the standard drum and matrix design. This appendix illustrates the design and construction features of the empty or zero matrix drum. Test matrix drums are constructed by inserting simulated matrix materials of appropriate weight and distribution throughout the open volume of the drum. The Program Coordinator will ensure that detailed specifications for each of the individual matrix drums are made available to program participants.

The Program Coordinator shall ensure delivery of the PDP standards and matrix drums to each measurement facility prior to the start of that facility's participation in PDP measurement activities. The measurement facility will be responsible for assigning a secure storage area for these components. The storage container area for the PDP standards must be secured with a tamper indicating device (TID) for the duration of any PDP test cycle. The purpose of this requirement is to ensure that the staff responsible for assay measurements are not able to examine the unused standards and infer the activity of the 
standards used in the current PDP samples. The SPT will coordinate with the site safeguards staff to enforce this requirement while complying with all site SNM requirements. The SPT assigned by the measurement facility will be available to inspect, inventory, and secure the standards, as well as to inspect matrices and drums for defects or damage during shipping. Appropriate arrangements will be made, before shipment, with safeguards and radiation safety organizations of each participant.

The Program Coordinator will notify each Assay Coordinator 2 weeks in advance of the planned shipping date for PDP standards and matrix drums. The PDP standards will be sent to the address and individual designated by the facility. Measurement facility address changes may be made by written notification to the Program Coordinator (with a copy to CAO) at least 2 weeks before the scheduled shipping date. Such notification must include a statement that the new designated individual is authorized by the site to receive and handle the radioactive standards for the program. Evidence of QA training and other minimum qualifications discussed in Section 6 of this document must also be presented.

Table 4. Waste forms identified in the Waste Isolation Pilot Plant Transuranic Waste Baseline Inventory Report.

1. Solidified inorganic waste

2. Salt waste

3. Solidified organic waste

4. Soil

5. Unspecified metal waste (metal waste other than lead and/or cadmium)

6. Lead/cadmium metal waste

7. Inorganic nonmetal waste

8. Combustible waste

9. Graphite waste

10. Heterogeneous waste

11. Filter waste 
Table 5. Waste matrix drums planned for the NDA PDP.

1. Zero Matrix (empty) drum

2. Combustible waste

3. Glass waste

4. Metal waste

5. Solidified inorganic waste

6. Solidified organic waste

7. Heterogeneous waste

\subsection{PDP Sample Components Receipt}

\subsection{1}

Immediately on receipt of PDP standards and matrix drums, the SPT will locate the shipping manifest.

\subsection{2}

The SPT will verify that the standards and matrix drums actually received match those listed on the shipping manifest both by serial number and physical description. The SPT will verify that components have not been damaged during shipping.

1. If there is a discrepancy, the SPT will notify the Program Coordinator immediately and wait until further instructions are received.

2. If there are no discrepancies, the SPT will indicate receipt: by signing any required shipping manifests or return receipts at the appropriate locations.

\subsection{3}

If required by the shipper, the SPT will return the signed shipping manifest to the designated addressee.

\subsection{4}

The SPT will ensure that all components are securely stored in the designated area.

\section{2 .5}

The SPT will maintain security on all PDP standards and shall not permit their use in any other activity prior to their first use in a PDP cycle.

\section{2 .6}

The SPT will ensure that all PDP standards are handled and stored in full compliance with all site requirements. 


\section{PDP TEST DRUMS}

\subsection{Responsibilities}

A two-person SPT, consisting of a PDP Standards Custodian and a PDP Standards Configuration Attestant, shall be assigned by each measurement facility. When selecting SPT members, the measurement facility must ensure that candidates, at a minimum, possess the following qualifications and experience:

1. Full-time employee of the measurement facility.

2. Independent of the measurement group being tested, that is, neither member of the SPT may participate in assay measurements of PDP samples that they have helped prepare.

3. QA trained, including site QA training and the training provided by the Program Coordinator for SPTs.

4. Qualified to handle radioactive materials (PDP Standards Custodian only).

The PDP Standards Custodian, as the lead member of the SPT, is responsible for coordination of on-site activities with safeguard organizations, radiation safety, and PDP measurement facility contacts. These activities will include, but are not limited to, PDP standard receipt, storage and retrieval of standards, inspection of stored materials (e.g., PDP matrix drums), PDP sample preparation, and PDP standard removal. In addition, the PDP Standards Custodian will serve as the principal liaison between the Program Coordinator and the measurement facility. In this capacity, the PDP Standards Custodian serves as the primary on-site point of contact for the Program Coordinator and is responsible for documentation control and problem reporting.

The PDP Standards Configuration Attestant is responsible for verifying the proper emplacement of PDP standards and performing security-related procedures with the samples. The PDP Standards Configuration Attestant will ensure that all operations executed by the PDP Standards Custodian are performed in accordance with the applicable standard preparation procedure. To perform these functions, the PDP Standards Configuration Attestant will witness all PDP standard loading and unloading operations and will seal loaded PDP sample drums using the provided serialized PDP sample security TIDs. The PDP Standards Configuration Attestant will inspect sample drums, (a) for tampering before any measurement, (b) during the distribution cycle by random spot checking, and (c) before PDP standard unloading. Other than the SPT, no observers of the PDP Sample Preparation process will be permitted without to prior permission of the Program Coordinator.

\subsection{Instructions for PDP Sample Preparation}

\section{2 .1}

At least 2 weeks prior to the scheduled start date for each PDP cycle, the Program Coordinator will forward a letter of instruction to each SPT. This letter of instruction will specify the locations, identification, and activities of each PDP standard to be inserted in each matrix drum to be used in that cycle. This information will be supplied on a PDP Sample Configuration Form (see Appendix D).

\section{2 .2}

The PDP Standards Custodian will identify the correct standards using the applicable site-specific sample preparation procedures. (Each site-specific sample preparation procedure provides the SPT with specifications for drum loading of standards.) The PDP Standards Configuration Attestant shall verify that the proper standards were selected for PDP matrix drum emplacement. 


\section{2 .3}

The PDP Standards Custodian will select the proper serial numbered 55-gallon matrix drum for insertion of PDP standards.

\subsection{4}

The SPT will coordinate the placement of PDP matrix drums and PDP sample standards into a designated sample preparation area.

\subsection{5}

The PDP Standards Custodian will examine all required PDP sample components (i.e., matrix drums, PDP standards) using the site-specific sample preparation procedure. The objective of the pre-load examination is to determine if any components are missing or damaged.

If there is a damaged or missing PDP sample component, the SPT team vill determine if a spare component can be retrieved from on-site inventory. If the SPT can acquire a spare component, the missing or damaged item will be replaced with the spare. Otherwise, the Program Coordinator will be notified immediately by the PDP Standards Custodian and the SPT team will await further instructions.

\subsection{6}

The PDP Standards Custodian will insert each standard into the identified position of the source insert fixture, as delineated in the site-specific sample preparation procedure. Each team member shall independently verify that the source positioning is correct and initial and/or sign the site-specific PDP Sample Configuration Form, as appropriate.

\subsection{7}

Once all standards have been positioned and the placement verified, the PDP Standard Configuration Attestant will seal the PDP sample with the appropriate serialized tamper indicating device.

\subsection{8}

The PDP Standards Custodian will security seal the PDP Sample Information Form (see Appendix D) and affix it to the top of the sample drum. The PDP Sample Information Form provides relevant standard information, including standard activities and standard locations within the PDP sample. It may be opened only during an emergency or at sample disassembly. If the security seal for the PDP Sample Information Form is broken before PDP sample disassembly, all analysis data for that sample will be considered invalid. A site specific form may be used in place of the PDP Sample Information Form if required by the site staff responsible for tracking and accounting for SNM.

\section{2 .9}

The PDP Standards Custodian will prepare a PDP Sample Custody Form for Nondestructive Assay (Custody Form, see Appendix D) for sample acceptance by the measurernent facility.

\section{2 .10}

Steps 6.2.2 through 6.2.9 are repeated for each PDP sample preparation.

\subsubsection{1}

The PDP Standards Custodian will return any unused materials to storage and secure the PDP standards storage area with a TID. 


\section{2 .12}

The PDP Standards Custodian will transfer the PDP samples and Custody Forms for Nondestructive Assay to the Assay Coordinator and obtain a receipt signature from the Assay Coordinator for each prepared PDP sample.

\section{2 .13}

After the signature of the Assay Coordinator is obtained on each Custody Form, the following materials must be returned to the Program Coordinator (or designee):

- the originals of the PDP Sample Configuration Forms,

- the originals of the PDP Sample Information Forms, and

- one copy of each PDP Sample Custody Form for Nondestructive Assay.

\subsubsection{4}

If multiple assay systems are to be qualified at one site, it will be the responsibility of the Assay Coordinator to coordinate schedules and transfers between the various assay systems at the site. If there is insufficient time to make all measurements for the number of assay systems planned for participation, the Assay Coordinator should request an extension pursuant to Section 7.2.3.

\subsubsection{5}

The SPT will maintain all records of PDP Sample preparation in strict confidence until that PDP Sample has been released for disassembly by the Program Coordinator.

\section{ANALYTICAL AND DATA REPORTING REQUIREMENTS}

This section describes activities required of participating measurement facilities for PDP sample acceptance, analysis, and reporting.

\subsection{PDP Sample Acceptance}

\subsection{1}

The participating measurement facility will designate a measurement group point of contact, referred to as the Assay Coordinator, who is responsible for accepting PDP samples and ensuring that chain of custody protocols are followed.

\subsection{2}

On initial receipt the Assay Coordinator will inspect the condition of the drum seals by checking the tamper-indicating devices (TIDs) on each PDP sample to ensure they are intact. If a problem exists with the integrity of any TIDs, the drum should be rejected and returned to the SPT.

\subsection{3}

The Assay Coordinator shall confirm the accuracy of each Custody Form. 


\subsection{4}

If TIDs are intact and all data are in order, the Assay Coordinator will review, sign, and date each

Custody Form. This custodial signature signifies measurement facility arceptance of the PDP sample. The date of signature indicates the validated date and time of sample receipt. At this point the SPT will pull two copies of each Custody Form, retaining one copy and returning the other copy to the Program Coordinator.

\subsection{5}

All subsequent transfers of the drums within the measurement group and ultimate return of the drums to the SPT will be documented on the PDP Sample Custody Form accompanying the drum.

\subsection{Analysis}

\subsection{1}

The measurement facility will analyze the contents of each PDP sample six times using the procedures that are planned for use in the WIPP waste characterization program. These procedures must have been internally demonstrated to meet the QAOs in accordance with QAPP requirements and the procedures must have been approved within the site-specific system for control of operating procedures. The PDP sample must be completely removed and replaced between sequential measurements.

\subsection{2}

Analyses should be completed and reported as soon as possible, but in any case must be forwarded to the Program Coordinator within 28 days after validated time of sample receipt (VTSR). The signature date by the Assay Coordinator of the PDP Sample Custody Form for Nondestructive Assay represents the VTSR and should be considered day 0 when calculating calendar days to determine the reporting due date.

\subsection{3}

If a participant's analyses will not be reported by the due date and the participant desires an extension, he or she must notify the Program Coordinator as soon as possible and request that an extension be granted. The Program Coordinator cannot grant an extension; however, the Program Coordinator will request that the CAO grant an extension. The Program Coordinator will notify the measurement facility of the status of their request. All extensions must be requested and granted before the due date. If an extension has not been granted prior to the due date, the Program Coordinator may make the standard configuration and content of each PDP sample known at any time thereafter. Any measurement facility that had not yet reported will then not be able to use these data to qualify for analysis of WIPP samples.

Schedule extensions for conducting a cycle or for submittal of testing data for a cycle can only be granted via written authorization by the CAO (either directly or through the Program Coordinator).

Extensions will only be granted under extremely exigent circumstances beyond the planning control of the participating facilities. Failure of a participant to submit testing data by the required due date may be cause for disqualification of that participant in the testing cycle. 


\subsection{Reporting}

\subsection{1}

A summary of all isotopes listed in Table 1, for all replicate analyses, will be sent by the participating measurement facilities to the Program Coordinator. The activities of detected isotopes will be reported irrespective of the relationships of those activities to detection limits quoted or demonstrated for the program. The following specifications apply to the summary report.

7.3.1.1 Reports shall be forwarded directly to the Program Coordinator's Technical Liaison. Express mail or overnight delivery service is preferred, but in any case all analytical reports to the Program Coordinator shall be postmarked or shipped no later than 28 calendar days after the VTSR.

7.3.1.2 Analytical reports will be submitted for each PDP sample. Reports are required in hard copy and in a prescribed computer readable format.

7.3.1.3 Reports shall consist of at least the following information for each determination:

1. Identification of the reporting measurement facility.

2. Identification of the PDP Distribution Cycle and program component for which the data are being reported.

3. Identity of the drum by the serial number from the PDP Sample Custody Form for Nondestructive Assay or analogous identification of lab blanks.

4. Any additional identification assigned to the PDP sample by the measurement facility.

5. Identification of the instrument system and method used for each isotope (sites using a set of constant isotope ratios will so indicate on the report form).

6. Identification of the replicate number corresponding to the analytical data.

7. Identity and activity in Curies for each target isotope identified.

8. Counting uncertainty and estimated total uncertainty for each identified isotope.

9. Total ${ }^{239} \mathrm{Pu}$ fissile gram equivalents $(\mathrm{g})$ and associated total uncertainty.

10. Total alpha activity and associated total uncertainty (Curies).

11. Thermal power and associated uncertainty (W).

12. Date and time of NDA.

7.3.1.4 The results of each individual analysis must be reported, not the average of the six determinations.

7.3.1.5 The Performance Demonstration Program Report Form for Nondestructive Assay from Appendix D or a reasonable facsimile should be used to report the data to the Program Coordinator. Continuation sheets may be used if the comments of the measurement facility exceed the allocated space on the report form.

7.3.1.6 A computer-readable electronic copy of the reporting data for all PDP samples must be | provided by the measurement facility on a diskette or by direct transmission. All participants in the NDA 
PDP are provided with a copy of an Electronic Data Recorder (EDR). The EDR is a tool for generating the electronic deliverable in the correct format and will also print a copy of the report. Regardless of the method of transmission of the EDR generated files, signed hard copies of the report forms must also be provided for the QA records.

7.3.1.7 Corrections to data will be accepted if received in writing before or on the report due date. Data may also be corrected by facsimile up to 8:00 p.m. (Eastern Standard or Eastern Daylight Time, as applicable) on the report due date, if followed by express mail or overnight courier transmission of the original hard copy and the electronic deliverables disk. Verbal corrections to data will not be accepted.

7.3.1.8 The reports will be signed by a measurement facility staff member assigned this responsibility. Reports should contain any other information deemed relevant by the measurement facility.

\subsection{Completion and Disassembly}

\subsection{1}

After the measurements are complete and the PDP samples are returned from the Assay Coordinator, the SPT will hold all PDP Samples in secure storage until the scoring report is completed by the Program Coordinator and the authorization to disassemble has been received.

\subsection{2}

When authorization has been received, the PDP samples may be disassembled by the following procedure:

7.4.2.1 The PDP Standards Custodian will retrieve the appropriate PDP Sample Custody Form for Nondestructive Assay, the PDP Sample Configuration Form for the PDP Sample to be disassembled, and a new PDP Sample Disassembly Form (see Appendix D).

7.4.2.2 The PDP Standards Custodian will determine the condition of the security seal on the PDP Sample Information Form (see Appendix D) on the top of the sample drum. The condition will be noted on the PDP Sample Disassembly Form. If the seal is not already broken, the PDP Standards Custodian will break the security seal and remove the PDP Sample Information Form from the top of the sample drum. If the security seal for the PDP Sample Information Form is broken before PDP sample disassembly, all analysis data for that sample will be considered invalid.

7.4.2.3 The PDP Standards Custodian will determine the condition of the source insert fixture TID on the sample drum lid locking ring. The condition will be noted on the PDP Sample Disassembly Form. If the TID is not already broken, the PDP Standards Custodian will break the TID and remove the source insert fixture security wire allowing the fixtures containing the PDP Standards to be removed (see ( Appendix C). If the TID is broken before PDP sample disassembly, all analysis data for that sample will be considered invalid.

7.4.2.4 The PDP Standards Custodian will remove each standard from its position in the source insert fixture. Each team member shall independently verify that the source positioning is correct against the PDP Sample Information Form and the PDP Sample Configuration Form.

7.4.2.5 If there is a damaged, missing, or misplaced PDP sample component, this information must be recorded on the PDP Sample Disassembly Form.

7.4.2.6 Once all standards have been removed and the placement verified, the Standards Custodian will coordinate the return of the PDP matrix drums and the PDP sample standards to the 
designated, secured storage area under the facility's normal storage procedures.

\subsection{3}

The disassembly operations will be documented on the PDP Sample Custody Form as the "Disposition".

\subsection{4}

The completed originals of the Custody Form and the Disassembly Form shall be returned immediately to the Program Coordinator by the PDP Standards Custodian. If any TID, custody seal, drum, or standard shows evidence of tampering, the PDP Standards Custodian shall ensure that the evidence of tampering is secured and that the condition is noted on the forms. The PDP Standards Custodian shall then notify the Program Coordinator and await further instruction.

\section{NDA PERFORMANCE}

The scoring system for the PDP is a pass-fail system. In order to pass a specific test, the measurement must fall within the specified test criteria for the PDP (Table 3). In order to pass the PDP cycle, the measurement assay system must pass all individual tests.

NDA performance will be evaluated in the areas of precision and bias. The definitions of precision, bias, total accuracy, and total uncertainty generally follow the prescription found in the QAPP. Precision is defined in this context to mean the standard deviation from several replicate measurements of the identical PDP sample under fixed conditions. Bias is the systematic error component of the total uncertainty. Instrument bias is taken to mean the bias of a particular instrument under essentially ideal conditions as practically as can be obtained. This bias is specific to the instrument in isolation from interfering effects such as matrix effects. Instrument bias will be estimated for the noninterfering samples by determining the measurement accuracy of a series of replicate measurements. It is intended as a baseline determination and control on the instrument itself, independent of complicating measurement conditions.

Total accuracy is defined as the closeness of the mean results obtained from a measurement system to the known or accepted reference or standard values. In this program total accuracy is estimated from the measurement results for PDP samples that include sources of variance in addition to those measured in the zero matrix drums. Additional variance sources include, matrix variations, isotopic compositions, spatial distributions, contaminating radionuclides and other interfering effects. The determination of an average total accuracy will be used as an estimate of bias for interfering matrices.

Total uncertainty is the total measurement error from all variance sources, including the precision, the instrument bias, and interference effects such as variable matrices, isotopic compositions, spatial distributions, contaminating radionuclides, and any other interfering effect. This definition includes sources of error that will not be testable within the limitations of the PDP. In addition to successful participation in the PDP, the QAPP contains requirements to determine the total measurement uncertainty and to demonstrate compliance with the QAO for total bias by a propagation of error. Successful participation in the PDP is a necessary, but not sufficient, condition for fully demonstrating compliance with this QAO.

Both precision and bias will be measured for all PDP samples. Different criteria have been established in the noninterfering and interfering matrices. Precision and bias for the noninterfering matrix will be . determined from measurements on the zero matrix drum. Precision and bias determinations for all simulated waste matrices will be compared to the criteria for interfering matrices.

The basis for the scoring system of the PDP is to ensure that the QAPP QAOs are satisfied at the 95\% confidence level and for a reasonable number of replicate samples. A reasonable number of samples is 
defined as six replicate samples in this instance. This number of determinations will permit an adequate statistical evaluation without overburdening the measurement participants with excessive replicate measurements.

\subsection{Scoring System}

Because nondestructive assay involves an inherently probabilistic process, the specification of a scoring system to demonstrate compliance with the QAPP QAOs must be based on probabilistic confidence intervals. The underlying distribution of any nondestructive assay measurement is assumed to be normal. However, the variance of this normal distribution, which is the true precision of the nondestructive assay instrument, is a priori unknown; and is one of the performance parameters that is measured by the PDP.

The instrument precision is equal to the standard deviation of the underlying measurement distribution. It is measured by making several replicate measurements on a single known PDP sample. The measured standard deviation is generally not identical to the underlying distribution standard deviation, but the two are related by the chi-square distribution. Similarly, the measured, or the sampled mean, will be related to the mean of the underlying distribution by the Student's $t$ distribution, because the underlying variance is not known. Because only six determinations are required in the PDP in contrast to the QAPP which requires fifteen determinations, the numerical criteria for both the precision and the bias are adjusted to ensure the same level of confidence that the theoretical QAPP QAOs are demonstrated in each case.

Precision is expressed as the measured percent relative standard deviation (\%RSD) for the sample. Relative precision values used in the PDP are calculated relative to the reference (or known) value for the PDP sample. This permits the test of precision to be equitable among the sites and independent of the measurement bias. Referencing the relative standard deviation to the known value also preserves the assumption of the chi-square definition integral to the statistical arguments in Appendix A. For the NDA PDP the \%RSD is determined by

$$
\% R S D=100 * \frac{\sqrt{\frac{\sum_{i=1}^{n}\left(x_{i}-\bar{x}\right)^{2}}{n-1}}}{\mu_{0}}
$$

where:

$$
\begin{array}{lll}
x_{i} & = & \text { a sample value } \\
\mathbf{n} & = & \text { the number of measurements } \\
\mu_{O} & = & \text { actual known PDP sample value } \\
\bar{x} & = & \text { the average sample value, defined by }
\end{array}
$$

$$
\mid \bar{x}=\frac{\sum_{i=1}^{n} x_{i}}{n} .
$$

A chi-square distribution is assumed for the evaluation of precision. To evaluate the bias in the mean or the total accuracy, a Student's $t$ distribution is assumed. Two parameters need to be specified: the required confidence limit and the required number of replicate samples (also known as the degrees of freedom plus one).

Compliance with the QAPP QAOs requires demonstration at the $95 \%$ confidence level, consistent with the QAPP and other sections of the PDP. 
The degrees of freedom were selected to be five (i.e., six replicate measurements). The number of replicates determines the width of the chi-square and Student's $t$ distributions. As the number of replicate samples increases, the width of the distributions decrease. However, for large numbers of replicate samples the improvement diminishes. Six replicates were selected as a compromise between maintaining a reasonable number of samples and using any larger numbers to reduce the width of the distribution gradually. The required measured precision for the noninterfering matrix was then calculated from the assumption that the PDP and the QAPP QAO precision criteria both represent the $95 \%$ upper confidence bounds of a chi-squared distribution, but at 5 and 15 degrees of freedom, respectively. Column 4 of Table 3 shows the required measurement precision obtained from these calculations. The limits in Column 5 of Table 3 were modified further based on the additional sources of uncertainties in the interfering matrix drums.

For the bias measurements, the upper and lower $95 \%$ confidence limits for the two-sided Student's $t$ distribution were used to modify the limits in Columns 6 and 7 of Table 3. For scoring purposes, the bias limits in Table 3 are reduced by the half width of the $95 \%$ confidence bound of the Student's t distribution. Assuming six replicate samples and a $95 \%$ confidence level, this equation can be expressed as

$$
\left(\% R_{L}+1.05 \% \% R S D\right) \leq 100 x \frac{\bar{x}}{\mu_{o}} \leq\left(\% R_{H}-1.05 \% \% R S D\right)
$$

where:

$$
\begin{array}{lll}
\% R_{L} & = & \begin{array}{l}
\text { low } \% \text { recovery limit specified in Table 3, columns } 6 \text { or } 7 \text { (noninterfering } \\
\text { or interfering), as appropriate }
\end{array} \\
\% R_{H} \quad=\quad \begin{array}{l}
\text { high } \% \text { recovery limit specified in Table 3, columns } 6 \text { or } 7 \text { (noninterfering } \\
\text { or interfering), as appropriate }
\end{array}
\end{array}
$$

Other terms are as indicated above. This condition requires that

$$
1.05 * \% R S D \leq / 100-\% R_{L, H} /
$$

Otherwise, the test will fail.

Appendix A discusses the statistical bases for the scoring criteria in detail.

\subsubsection{Bias of Quantitation of Simulated TRU Wastes}

8.1.1.1 Purpose. NDA results for replicate analyses for PDP samples of known alpha activity will be used to determine the bias with which a measurement facility can quantitate the total alpha activity. Bias is estimated from a determination of the total accuracy of a measurement. The total accuracy is the closeness of the mean results obtained from a measurement system to the known or accepted reference or standard values. In this program total accuracy is determined from the measurement results for PDP samples that include variance and bias elements in addition to those associated with the zero matrix drums including effects due to sample matrix and isotope characteristics.

8.1.1.2 Criteria. The results reported for total alpha activity shall not deviate from the reference value, $\mu_{0}$ (true sample value), by more than the amount specified in Equation (3) using the values for $\% \mathrm{R}$ specified in Column 7 of Table 3, bias for an interfering matrix. The selection of the appropriate criteria specified in Table 3 is based on the known total alpha activity range in which the prepared PDP sample falls. 
8.1.1.3 Method. The bias of quantitation shall be computed by measuring six replicate samples and calculating the mean, $\bar{x}$, Equation (2), and the relative standard deviation, RSD, Equation (1). The measurement will pass this criterion if Equation (3) is satisfied and will fail if Equation (3) is not satisfied. The values for \% $\mathrm{R}$ in Equation (3) will be the low and high values specified in the Total bias column of Table 3 that corresponds to the total alpha activity range in which the prepared PDP sample falls.

8.1.1.4 Actions. For PDP samples for which the total bias is outside the limits established in Table 3 for the activity range tested, the measurement facility will be judged as unable to quantitate for that specific activity range. The impact of exceeding an action level on overall measurement facility performance is given in Section 8.1.4. In accordance with Section 9, the site Project Manager has responsibility to ensure that appropriate corrective actions are taken when necessary.

\subsubsection{Instrument Bias}

8.1.2.1 Purpose. NDA results for replicate analyses for PDP samples of known activity in zero matrix drum with known source isotopics will be used to determine the instrument bias with which a measurement facility can measure the total alpha activity. In this particular instance, the instrument bias will be estimated from the total accuracy determined for a noninterfering; sample.

8.1.2.2 Criteria. The results reported for total alpha activity shall not deviate from the reference value, $\mu_{o}$ (true sample value), by more than the amount specified in Equation (3) using the values for $\%$ R specified in Column 6 of Table 3, bias for an noninterfering matrix. The selection of the appropriate criteria specified in Table 3 is based on the known total alpha activity range in which the prepared PDP sample falls.

8.1.2.3 Method. The method for determining the instrument bias shall be identical to the method for the bias of quantitation of simulated TRU wastes (Section 8.1.1.3), except that the reference values used from Table 3 will be from the noninterfering bias column. Also, the bias determination will be done only on PDP samples assembled from the zero matrix drum.

8.1.2.4 Actions. The actions for the instrument bias determination are identical to the actions for the determination of the bias of quantitation of simulated TRU wastes (Section 8.1.1.4).

\subsubsection{Precision of Replicate Determinations}

8.1.3.1 Purpose. To demonstrate compliance with the QAOs for precision by replicate processing, NDA results from replicate analyses of a PDP sample of known alpha activity will be used to determine the precision with which a measurement facility can quantitate total alpha activity.

8.1.3.2 Criteria. The results reported for total alpha activity from replicate measurements of an identical sample shall not exhibit a measured relative standard deviation greater than that specified in Table 3, Column 4 for the zero matrix drum and Column 5 for all other simulated waste matrix drums.

8.1.3.3 Method. The analytical results from the six replicate measurements of an identical sample are used to calculate the relative standard deviation using Equation (1). The measured standard deviation is then compared with the values listed in Table 3 . For the zero matrix drum, if the measured value is less than that specified in Table 3 , Column 4 , the measurement passes this test. For all other simulated waste matrix drums, if the measured value is less than that specified in Table 3 , Column 5 , the measurement passes this test.

8.1.3.4 Actions. For any sample for which results exceed the appropriate QAO for precision in any sample activity range (see Table 3 ), the measurement facility will be judged as unable to quantitate for that specific alpha activity range. The impact of exceeding an action level on overall measurement 
facility performance is given in Section 8.1.4. In accordance with Section 9, the site Project Manager has responsibility to ensure that appropriate corrective actions are taken when necessary.

\subsubsection{Overall Performance}

8.1.4.1 Purpose. Measurement facility performance on the entire set of PDP samples will be used to assess general problems that may affect the measurement facility's ability to analyze total alpha activity within a 55-gallon waste drum. This conclusion could result in a holding period during which the measurement facility would not analyze WIPP samples until the causes of the problems are identified, corrective action is taken, and the efficacy of the corrective action is demonstrated.

8.1.4.2 Criteria. The criteria used for the evaluation of overall measurement facility performance is specified, as follows: Measurement facilities must pass all performance criteria for an activity range demonstrated by this program to be considered qualified to perform NDA on WIPP samples for that activity range tested.

8.1.4.3 Method. The NDA results for the PDP samples must meet all of the criteria identified in sections 8.1.1.2, 8.1.2.2, and 8.1.3.2 of this Program Plan.

8.1.4.4 Special Scoring. On occasion, circumstances may dictate that special PDP samples be distributed for the evaluation of specific analytical conditions or problems. Specific PDP samples may be prepared by the SPT to test an individual isotope or a small group of isotopes. Under these circumstances, the target isotopes(s) will be identified and only the target isotopes(s) will be scored. Measurement facilities will neither be credited nor penalized for analytical data submitted for other isotopes not identified as targets in that PDP sample or for data submitted for target isotopes known to be absent in that PDP sample.

8.1.4.5 PDP Sample or /sotopic Disqualification. If the preponderance of evidence from the participating measurement facilities supports a conclusion that a PDP sample was inadequate to demonstrate compliance with the criteria of the PDP, the Program Coordinator may judge the data for that PDP sample to be inappropriate for use in the evaluation of performance for that particular performance demonstration.

8.1.4.6 Actions. The site Project Manager has the responsibility of ensuring that appropriate corrective action measures are implemented when a measurement facility exceeds an action limit. The following are considered minimum mandatory measures that must be implemented when action limits are exceeded.

8.1.4.6.1 -If a measurement facility fails the criteria of 8.1.1.2, 8.1.2.2, or 8.1.3.2 applicable to a given cycle, the measurement facility will be judged to have exceeded an action level.

8.1.4.6.2 - Any measurement facility that has exceeded an action level shall cease analytical operations for certification of WIPP wastes for the range for which the criteria were not met as well as any ranges not yet tested. The measurement facility may not begin analytical operations for certification of WIPP wastes until approval to do so has been obtained from CAO. To obtain this approval, the facility must submit a report to $\mathrm{CAO}$ containing the following items:

1. the results of an investigation of the cause of the failure(s);

2 description of any corrective actions completed and/or proposed as a result of the investigation;

3. supporting data sufficient to demonstrate that the same problems will not recur;

4. a plan and schedule for the disposition for all potentially affected radioassay data, for example, any data collected prior to the first PDP cycle, between a successful and a failed 
PDP cycle, or between completion of a PDP cycle and the issuance of the report for that cycle. (Such data shall be treated as a potentially nonconforming item under the facility's QA program.);

5. an assessment of the impact of the measurement facility's approval status for NDA on waste characterization activities at the site; and,

6. a proposed mechanism for obtaining approved status from $\mathrm{CAO}$, including a request for approval in a supplemental PDP cycle or for approval with waiver of a supplemental cycle.

8.1.4.6.3 - The CAO may elect to grant conditional approval for a measurement facility to perform waste characterization analyses for this program if such conditional approval will not compromise the overall quality of the data being generated for the program. Such conditional approvals will be granted with appropriate limitations and conditions to guarantee that suspect data will not be used in the program.

8.1.4.6.4 -Prior to granting approval to the facility to continue analytical operations for certification of WIPP wastes, CAO may require that the measurement facility demonstrate adequate performance, that is, meet the scoring criteria described in 8.1.4.2 on ancther set of PDP samples If this requirement is invoked, CAO may direct that a supplemental cycle be conducted or that approval be withheld pending participation in the next regularly scheduled cycle of the PDP. CAO may elect not to invoke this requirement if:

1. The measurement facility can prove that the cause of its failure to meet performance criteria resulted purely from calculational errors and that appropriate control measures have been initiated to prevent recurrence of the errors; or

2. CAO concludes that such a waiver represents only negligible risk to the integrity of program data.

Section 9.3 discusses the circumstances that will be considered by $\mathrm{CAO}$ in determining the need and schedule for supplemental cycles to the NDA PDP.

\section{REPORTING OF PERFORMANCE DATA}

\subsection{Summary of Data}

The Program Coordinator shall review and evaluate the results, compile them into a master summary, and deliver this summary to DOE-CAO within 3 weeks after the receipt of the last measurement facility data set or within 9 weeks of the last VTSR, whichever occurs first. The report due date will be extended by a time equivalent to any extension granted by the CAO under Section 7.2 .3 . The report summary shall include the values reported by the measurement facilities, the reference isotopic values, the acceptance ranges, and the pass or fail status of each individual measurement facility.

The $\mathrm{CAO}$, in conjunction with the Program Coordinator, will evaluate individual measurement facility performance and approve individual measurement facilities for participation in the WIPP waste characterization program. Depending on the results of the PDP, the generator site Project Manager(s) have the responsibility of ensuring that appropriate corrective action measures are taken. 


\subsection{Distribution of Data}

Copies of the summary report will be distributed to each of the DOE operations offices involved, each of the participating measurement facilities, and other individuals and organizations deemed appropriate by | the CAO. The CAO shall also provide written notification to the DOE operations offices regarding the adequacy and approval status of their participating measurement facilities.

\subsection{Backup PDP Samples}

A backup set of PDP samples can be prepared by the SPT approximately 4 weeks after measurement facilities are notified of their status. Measurement facilities that do not pass on the initial set of blind audit samples may request to have these samples prepared at their facility. Requests must be submitted in writing to the CAO and be accompanied by the report required in Section 8.1.4.6.2. If CAO authorizes a retest, the schedule of distribution, analysis, scoring, and approval/disapproval actions by CAO will be negotiated for each supplemental distribution. The schedule will be based on a review of impacts on the overall WIPP schedule and program costs and may include discussions with the potential participants. Timing and selection of measurement facilities for participation in supplemental distributions will be entirely at the discretion of the CAO. Primary consideration will be given to preventing adverse impacts on WIPP waste characterization and compliance schedules.

\subsection{Measurement Facility Status}

Once the CAO has made a determination of measurement facility status with respect to analyses that are required to demonstrate compliance with regulatory requirements, such status shall remain in effect until a new determination is made by the $\mathrm{CAO}$. Measurement facilities obtaining approved status through a supplemental distribution cycle must participate in the next regular distribution cycle to maintain their approved status. Treatment of radioassay data by facilities undergoing a change in status was discussed in Section 8.1.4.6.2.

\section{REFERENCES}

DOE. 1995. Performance Demonstration Program Plan for Analysis of Simulated Headspace Gases. DOE/CAO-95-1076, Revision 0, June 1995. Carlsbad, New Mexico, Carlsbad Area Office, U.S. Department of Energy.

DOE. 1996a. Transuranic Waste Characterization Quality Assurance Program Plan. CAO-94-1010, Revision 0, Interim Change, November 1996, Carlsbad, New Mexico, Carlsbad Area Office, U.S. Department of Energy.

DOE. 1996b. Performance Demonstration Program Plan for RCRA Constituent Analysis of Solidified Wastes. DOE/CAO-95-1077, Revision 1, March 1996. Carlsbad, New Mexico, Carlsbad Area Office, U.S. Department of Energy.

DOE. 1996c. Transuranic Waste Baseline Inventory Report. DOE/CAO-95-1121, Revision 3, June 1996. Carlsbad, New Mexico, Carlsbad Area Office, U.S. Department of Energy. 
DOE/CAO 94-1045

REVISION 1

May 1997

THIS PAGE INTENTIONALLY LEFTT BLANK 


\section{APPENDIX A \\ STATISTICAL BASIS FOR SCORING CRITERIA}




\section{STATISTICAL BASIS FOR SCORING CRITERIA}

\section{A1. Definitions}

Limits and bounds. In this discussion, two types of bounds or limits are referred to: (1) those specified in the quality assurance objectives that define the acceptable ranges for precision and accuracy of an assay system, and (2) the endpoints of $95 \%$ confidence intervals calculated for the actual precision or accuracy of a system. While the terms "limits" and "bounds" can be used interchangeably, to avoid confusion this discussion uses the term "limits" only in reference to the QAPP/PDP acceptable performance criteria. Similarly the term "bounds" is used only to describe the endpoints of calculated $95 \%$ confidence intervals.

Point estimate. A point estimate is the best single value estimate for the parameter of interest. Point estimates contrast with confidence bound estimates which are interval estimates (since they delineate bounds on confidence intervals). For accuracy (used to estimate bias) the point estimate is the calculated percent recovery. For precision the point estimate is the percent relative standard deviation.

\section{A2. Performance Criteria}

For a noninterfering matrix, the QAPP quality assurance objectives (QAOs) (Table A-1, Column 2) specify acceptable limits for the measured precision of a nondestructive assay system based on 15 replicate determinations. Precision is measured by percent relative standard deviation. The measured precision based on 15 replicates is only an approximation of the true system precision. Hence implicit in each QAPP QAO limit for the measured precision is a corresponding $95 \%$ upper confidence bound on the true system precision. These bounds are stated explicitly in Table A-1, Column 3. Precision criteria for the PDP tests, derived in relation to the upper confidence bounds in Column 3, as described below, are given in Columns 4 and 5.

Table A-1. Performance criteria for the NDA PDP.

\begin{tabular}{|c|c|c|c|c|c|c|}
\hline \multirow[t]{2}{*}{$\begin{array}{l}\text { Activity } \\
\text { Range in } \\
\alpha \text {-Curies }\end{array}$} & \multirow[t]{2}{*}{$\begin{array}{l}\text { QAO for } \\
\text { Precision } \\
\text { (@15 } \\
\text { Replicates })\end{array}$} & \multirow[t]{2}{*}{$\begin{array}{l}\text { Maximum } \\
\text { allowable } \\
\text { precision } \\
(95 \% \text { CB of } \\
\text { QAO) }\end{array}$} & \multicolumn{2}{|c|}{$\begin{array}{l}\text { Maximum Measured } \\
\text { PDP Precision } \\
\text { (@6 Replicates) }\end{array}$} & \multicolumn{2}{|c|}{$\begin{array}{l}\text { Maximum PDP QAOs for Bias } \\
\text { (Values for \% } \mathrm{R}_{\mathrm{L}} \text { and } \% \mathrm{R}_{\mathrm{U}} \\
\text { for use in Equation 11) } \\
\text { (@6 Replicates) }\end{array}$} \\
\hline & & & Noninterfering & Interfering & Noninterfering & Interfering \\
\hline $\begin{array}{l}>0 \text { to } \\
0.02\end{array}$ & 0.20 & 0.292 & 0.14 & 0.16 & $\begin{array}{c}\text { Low: } .75 \\
\text { High: } 1.25\end{array}$ & $\begin{array}{l}\text { Low: } .40 \\
\text { High: } 1.75\end{array}$ \\
\hline $\begin{array}{c}>0.02 \text { to } \\
0.2 \\
\end{array}$ & 0.15 & 0.219 & 0.105 & 0.12 & $\begin{array}{c}\text { Low: } .50 \\
\text { High: } 1.50 \\
\end{array}$ & $\begin{array}{c}\text { Low: } 30 \\
\text { High: } 2.00 \\
\end{array}$ \\
\hline $\begin{array}{l}>0.2 \text { to } \\
2.0\end{array}$ & 0.10 & 0.146 & 0.07 & 0.12 & $\begin{array}{c}\text { Low: } .75 \\
\text { High: } 1.25\end{array}$ & $\begin{array}{c}\text { Low: } .30 \\
\text { High: } 2.00\end{array}$ \\
\hline$>2.0$ & 0.05 & 0.073 & 0.035 & 0.06 & $\begin{array}{c}\text { Low: } .75 \\
\text { High: } 1.25\end{array}$ & $\begin{array}{c}\text { Low: } .50 \\
\text { High: } 1.50\end{array}$ \\
\hline
\end{tabular}


The percent recovery criteria for accuracy from the QAPP have been adopted for the PDP tests for the noninterfering matrix (column 6). The PDP criteria for bias for the interfering matrices (column 7) are less restrictive than the noninterfering case. They are, however, in some cases more restrictive than the QAPP total bias criteria because the PDP does represent a controlled test situation relative to actual drum assay.

\section{Precision criteria for Noninterfering Waste Matrices}

The true precision and accuracy of an assay system are unknown. We use test data to estimate performance. The more data we have the better our estimates. The PDP criteria for measured precision in Table A-1, Column 4 were derived based on the fact that obtaining the same upper confidence bounds listed column 3 but with only 6 replicates in the PDP requires that the acceptable measured precision values be adjusted downward compared to that allowable for 15 replicates.

For example, when only 6 replicates are used, a measured value of $18 \%$ for the relative standard deviation of an assay system in the low activity range, even though it is less than the $20 \%$ allowable with 15 replicates, does not necessarily mean the implicit quality assurance objective of an upper confidence bound of $29.2 \%$ has been met. In fact, the $95 \%$ one-sided upper confidence bound for this six replicate example is approximately $38 \%$--considerably higher than the allowable limit. Hence the allowable measured precision with only 6 replicates must be lower than that for 15 replicates.

Since the confidence bounds for percent relative standard deviation depend only on the standard deviation itself (assuming a fixed sample size), it is possible to determine ahead of time exactly how large a calculated PDP point estimate value can be and still have an associated upper one sided $95 \%$ confidence bound that meets the criteria in Column 3 of Table A-1. The fourth column in Table A-1 gives these maximum point estimate values. Thus it is this column to which the calculated PDP point estimate for relative standard deviation of measurements on noninterfering matrices should be compared. (Exactly how the values for interfering matrices in Column 4 were obtained are described below.) Note that comparing the PDP point estimate to the value in column 4 is exactly equivalent to comparing the associated upper one-sided $95 \%$ confidence bound to the value in column 3 . That is, a PDP point estimate of the value indicated in column 4 will have a $95 \%$ upper one-sided confidence bound equal to the value in column 3 . (Similar point estimate columns for instrument bias and total bias can not be calculated since the confidence bounds for percent recovery depend on both the percent recovery point estimate and the estimated standard deviation.)

\section{A.3 Calculating Limits for Measured Relative Precision}

The limits specified in Column 4 for relative precision (measured by relative standard deviation) are derived from confidence interval calculations for the variance (i.e., the square of the standard deviation) of a distribution. The derivation is described below. But first a word of caution is in order. There is much variation in the notation used from one statistics book to another in describing confidence intervals for variances, and in how tables of chi-square critical values are listed. In particular, what is defined as $1-\alpha$ below is defined as $\alpha$ in some texts. Furthermore, some chi-square tables give critical values based on upper tail probabilities while others give them based on lower tail probabilities. 


\section{General derivation}

Let $\sigma^{2}=$ the true variance and let $1-\alpha=$ the desired confidence value. Furthermore, let $s^{2}=$ the sample standard deviation, and $\chi^{2} \alpha, n-1$ be the critical value of a chi-square distribution with $n-1$ degrees of freedom above which $\alpha \%$ of the distribution lies (that is, the critical value for the upper $\alpha \%$ tail of the distribution). Then, assuming a normal distribution, a two-sided $(1-\alpha) \%$ confidence interval for the true variance is (e.g., Anderson, 1985)

$$
\frac{(\mathrm{n}-1) \mathrm{s}^{2}}{\chi_{\alpha / 2, \mathrm{n}-1}^{2}}<\sigma^{2}<\frac{(\mathrm{n}-1) \mathrm{s}^{2}}{\chi_{1-\alpha / 2, \mathrm{n}-1}^{2}}
$$

Based on this formula for the two-sided interval, the upper one-sided $(1-\alpha) \%$ confidence bound is

$$
\sigma^{2}<\frac{(\mathrm{n}-1) \mathrm{s}^{2}}{\chi_{1-\alpha, \mathrm{n}-1}^{2}}
$$

from which the corresponding bound for the true percent relative standard deviation can be calculated as

$$
\frac{\sigma}{\mu} 100 \%<\sqrt{\frac{(n-1) \frac{s^{2}}{\mu^{2}}}{\chi_{1-\alpha, n-1}^{2}}} 100 \%
$$

where $\mu$ is the true mean of the distribution.

For the PDP tests, $\mathrm{n}=6$ and $\chi^{2} 1-\alpha, \mathrm{n}-1=\chi^{2} .05,5=1.145$ in Equation 3. Substituting these values and the reference (or true) value of the PDP sample for $\mu$ in this formula gives an approximate upper one-sided $95 \%$ confidence bound for the percent relative standard deviation. If desired, this upper confidence bound can be directly compared to the numbers in column 3 of Table A-1 to determine if an assay system has met the relative precision criteria.

The numbers in column 4 of Table A-1 (to which the point estimates rather than the upper confidence bounds can be compared) are derived by comparing the right hand side of Equation 3 to the appropriate number in column 3 of Table A-1 and solving for $s / \mu$. As an example, for the low activity range this calculation begins with the $\mathrm{QAO}$ required inequality 


$$
\sqrt{\frac{(n-1) \frac{s^{2}}{\mu^{2}}}{\chi_{1-\alpha, n-1}^{2}}} 100 \%<29.2 \%
$$

Solving for $s / \mu$ gives

$$
\frac{s}{\mu} 100 \%<\sqrt{\frac{(.292)^{2} \chi_{1-a n-1}^{2}}{n-1}} 100 \%
$$

which for 6 samples and $95 \%$ confidence as specified in the PDP gives

$$
\frac{s}{\mu} 100 \%<\sqrt{\frac{(.292)^{2}(1.145)}{5}} 100 \%=14 \%
$$

Again substituting the reference (or true) value of the PDP sample for $\mu$, indicates that a calculated relative standard deviation of $14 \%$ or less meets the QAO for relative precision in the low activity range. Since the chi-square value and $n$ are the same for all activity levels, the column 4 values for the other activity levels are obtained simply by substituting the appropriate value from column 3 in place of .292 in Equation 6.

\section{Precision Criteria for Interfering Waste Matrices}

The QAPP QAOs are specified for a substantially noninterfering matrix. To determine rational precision scoring criteria for the interfering cases, it was necessary to establish some relationship to Program objectives that can be used as a basis for the PDP criteria for the interfering waste matrix drums. There are certain Program defined limits for which assay systems are used to ensure compliance. In particular, there are the 200 fissile gram equivalent (FGE) material limits for 55 gallon containers and the TRU waste activity definition used to discriminate TRU waste from low level radioactive waste (LLW). At the high end, the precision of the assay system should be reasonable for waste containers approaching the $200 \mathrm{FGE}$ limit to ensure that an excessive number of drums do not exceed the limit at the $95 \%$ confidence level. Similarly, the waste assay system should be sufficiently precise for containers of low TRU mass loading (i.e., in the vicinity of the $100 \mathrm{nCi} / \mathrm{gram}$ alpha activity criterion) to ensure that an unacceptable number of containers of TRU waste are not classified as LLW.

As a convenient base for determining precision criteria for interfering waste matrix drums, the compliance points in Table 9-1 of the QAPP (DOE 1996) were used. For the low activity range the nominal compliance point for meeting the QAPP precision and bias criteria is $100 \mathrm{mg}$ of weapons grade plutonium (WG Pu). An acceptable assay system should be capable of detecting and quantifying TRU waste in 55 gallon waste containers at a level of $35 \mathrm{mg} \mathrm{WG} \mathrm{Pu}$. When 
assaying a container at the compliance point of $100 \mathrm{mg} \mathrm{WG} \mathrm{Pu}$, we would like to be sure at the $95 \%$ confidence level that the assay system will not return a value less than $35 \mathrm{mg} \mathrm{WG} \mathrm{Pu}$. This provides reasonable protection against classifying TRU waste as LLW. Based on this rationale, two standard deviations would correspond to $65 \mathrm{mg}(100 \mathrm{mg}-35 \mathrm{mg})$. One Relative Standard Deviation would therefore be $32.5 \mathrm{mg} / 100 \mathrm{mg}$ or 0.325 . By substituting .325 in place of .292 in equation 6 , we obtain a value of 0.155 (rounded up to 0.16 ) for the measured precision criterion for six replicate determinations of an interfering matrix drum in the low activity range.

Using similar reasoning, a precision criterion can be assigned to the high mass region. In this case the nominal compliance point is $160 \mathrm{~g} \mathrm{WG} \mathrm{Pu}$. When assaying a container at the compliance point of $160 \mathrm{~g} \mathrm{WG} \mathrm{Pu}$, we would like to be sure at the $95 \%$ confidence level that the assay system will not return a value greater than $200 \mathrm{~g}$ WG Pu. This provides reasonable protection against mistakenly classifying a TRU waste drum as not shippable when in fact it does not exceed the limit. Based on this rationale, two standard deviations would correspond to 40 grams ( $200 \mathrm{~g}-160 \mathrm{~g}$ ). One Relative Standard Deviation would therefore be $20 \mathrm{~g} / 160 \mathrm{~g}$ or 0.125 . By substituting .125 in place of .292 in equation 6, we obtain a value of 0.0598 (rounded up to 0.06 ) for the measured precision criteria for six replicate determinations of an interfering matrix drum in the high activity range.

No compelling programmatic objectives argue for specific precision limits for the low middle and high middle ranges although some thermal limits will fall into these ranges for some waste forms. Therefore, it was felt that arbitrary limits based on consistency and continuity in the use of the assay systems would be adequate for these ranges. The precision criteria for the low middle and high middle ranges were set at 0.12 for the \%RSD of six replicate determinations.

\section{A.4 Calculating Confidence Bounds for Instrument Bias and Total Bias}

To compare an assay system's performance to the requirements for bias for the noninterfering and interfering test conditions requires calculating the $95 \%$ two-sided confidence bounds for the true parameter using the sample data. Based on a t-distribution, the $(1-\alpha) \%$ two-sided confidence bounds for the true mean assay system mean $\mu$ are (assuming a normal distribution):

$\bar{x}-t_{1-\alpha / 2, n-1} \frac{s}{\sqrt{n}}<\mu<\bar{x}+t_{1-\alpha / 2, n-1} \frac{s}{\sqrt{n}}$.

In terms of relative percent recovery, the bounds are

$$
\frac{\bar{x}-\mathrm{t}_{1-\alpha / 2, \mathrm{n}-1} \frac{\mathrm{s}}{\sqrt{\mathrm{n}}}}{\mu_{0}} 100 \%<\frac{\mu}{\mu_{0}} 100 \%<\frac{\overline{\mathrm{x}}+\mathrm{t}_{1-\alpha / 2, \mathrm{n}-1} \frac{\mathrm{s}}{\sqrt{\mathrm{n}}}}{\mu_{0}} 100 \%
$$

where $\mu_{0}$ is the known (or accepted) value. These lower and upper bounds must be greater than $\% \mathrm{R}_{\mathrm{L}}$ and less than $\% \mathrm{R}_{U}$ respectively, where $\% \mathrm{R}_{\mathrm{L}}$ and $\% \mathrm{R}_{U}$ are the appropriate lower and upper bounds from Table A-1 (column 6 or 7). As before, these calculated lower and upper bounds can be compared with the limits specified in Table A-1. Equivalently, bounds for the point estimates 
for percent recovery can be obtained by solving the required inequalities for percent recovery. The required inequalities are

$$
\frac{\bar{x}-t_{1-\alpha / 2, \mathrm{n}-1} \frac{\mathrm{s}}{\sqrt{\mathrm{n}}}}{\mu_{0}} 100 \%>\% \mathrm{R}_{\mathrm{L}} \text { and } \frac{\overline{\mathrm{x}}+\mathrm{t}_{1-\alpha / 2, \mathrm{n}-1} \frac{\mathrm{s}}{\sqrt{\mathrm{n}}}}{\mu_{0}} 100 \%<\% \mathrm{R}_{\mathrm{U}}
$$

which, on solving for relative percent recovery gives

$$
\% \mathrm{R}_{\mathrm{L}}+\frac{\mathrm{t}_{1-\alpha / 2, \mathrm{n}-1} \frac{\mathrm{s}}{\sqrt{\mathrm{n}}}}{\mu_{0}} 100 \%<\frac{\overline{\mathrm{x}}}{\mu_{0}} 100 \%<\% \mathrm{R}_{\mathrm{U}}-\frac{\mathrm{t}_{1-\alpha / 2, \mathrm{n}-1} \frac{\mathrm{s}}{\sqrt{\mathrm{n}}}}{\mu_{0}} 100 \%
$$

With 6 samples, $\mathrm{n}=6$, and the corresponding $\mathrm{t}$ value (for $95 \%$ two-sided confidence bounds) is 2.571. So the equations simplify to

$$
\% \mathrm{R}_{\mathrm{L}}+\frac{1.05 \mathrm{~s}}{\mu_{0}} 100 \%<\frac{\overline{\mathrm{x}}}{\mu_{0}} 100 \%<\% \mathrm{R}_{\mathrm{U}}-\frac{1.05 \mathrm{~s}}{\mu_{0}} 100 \%
$$

\section{Reference}

Anderson, R. L. (1987). Practical Statistics for Analytical Chemists. New York, Van Nostrand Reinhold. 


\section{APPENDIX B}

\section{Specifications for Radioactive PDP Standards}




\section{Appendix B}

\section{Specifications for Radioactive PDP Standards}

This appendix delineates the general characteristics of the performance demonstration program (PDP) standard design. Several versions of standards are used in the program although all have the same external dimensions to properly fit the insert tube fixtures. The initial standards were weapons-grade plutonium dioxide ( $\mathrm{WG} \mathrm{PuO}_{2}$ ) material uniformly mixed in diatomaceous earth that was encapsulated in a dual stainless steel cylinder configuration. The bottom end of both the outer and inner seamless tubes have electron beam welded endcaps. The $\mathrm{WG} \mathrm{PuO}_{2}$ /diatomaceous earth mixture was dispensed into the inner cylinder, packed and stabilized with a press fitted frit 0.25 inches in height. The top endcap was then pressed in and welded using a tungsten inert gas method. The assembled inner tube was inserted into the outer tube and the top endcap is similarly welded in place. An assembled PDP standard is illustrated in Figure B-1. Other standards in the PDP use the radioactive materials discussed in Section 5.1. Some standards will use an inert matrix other than diatomaceous earth such as a carbon felt matrix to provide for more secure immobilization and/or precise placement of the radioactive material.

The dimensional and material attributes of the PDP standard were derived as a function of performance demonstration program objectives, nondestructive waste assay system response characteristics, and practicalities of fabrication. A complete PDP standard specification with supporting analyses is provided in the Lockheed Martin Idaho Technologies Company document, "Performance Demonstration Program for Nondestructive Assay for the TRU Waste Characterization Program, Initial Cycle Source Design", (INEL-94/0104).

The as specified PDP standard configuration complies with the following general requirements.

1. PDP standards must be physically stable and invariant with time in a well defined geometry.

2. The PDP standard configuration must facilitate convenient loading of the standards into the PDP matrix drum.

3. The PDP standard dimensions must allow for the simulation of multiple source spatial geometries within the PDP matrix drum.

4. The PDP standard encapsulation integrity must comply with all applicable standards and be acceptable for transportation and storage at participating sites.

5. The PDP standard design must accommodate available fabrication technologies at a reasonable cost. 


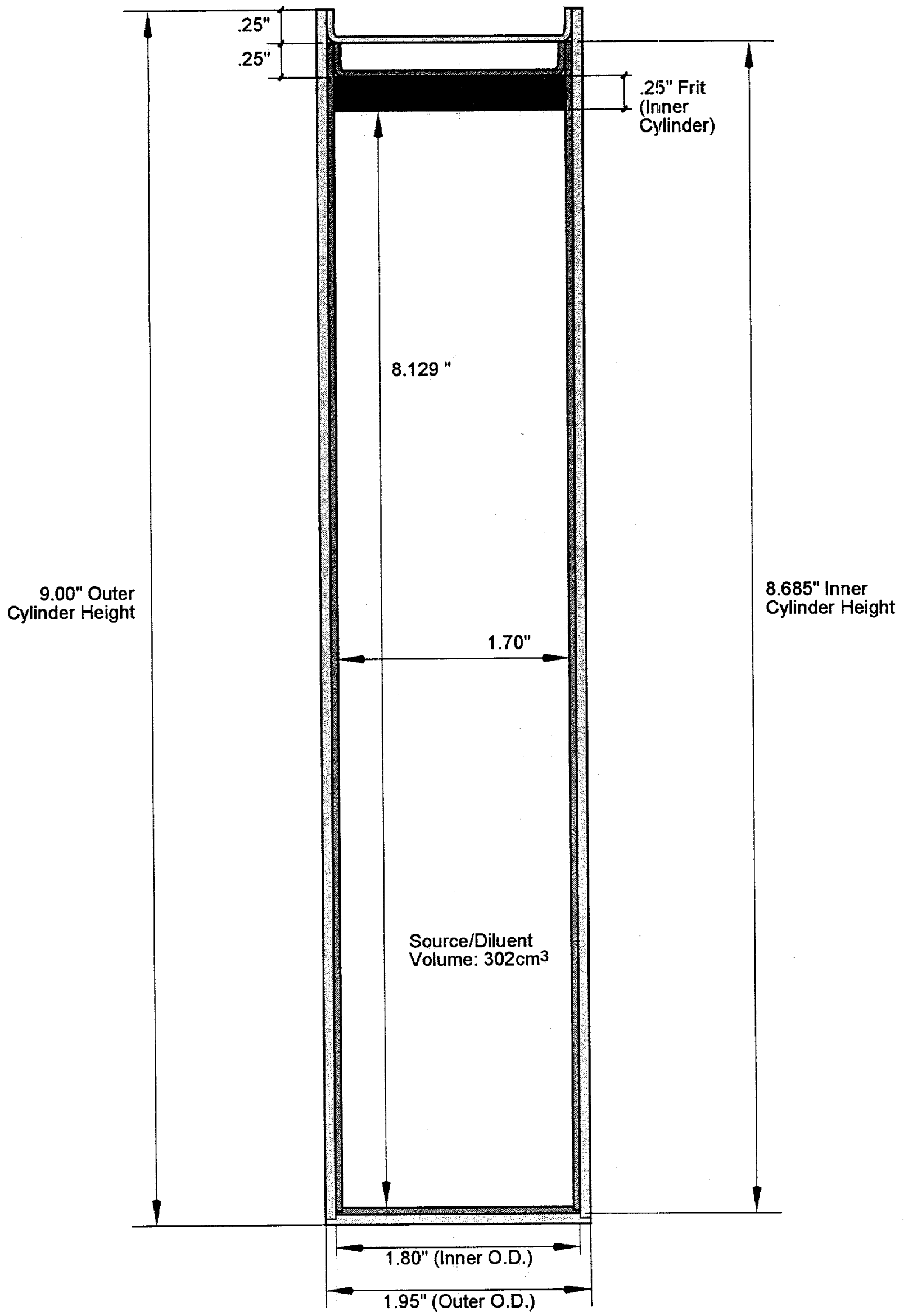

May 1997

8.685 " Inner

Cylinder Height

Figure B-1 PDP Standard Configuration

B -4 


\section{APPENDIX C \\ MATRIX DRUM SPECIFICATIONS}




\section{Appendix C}

\section{Matrix Drum Specifications}

This appendix provides the detailed design of the zero matrix drum for the nondestructive assay performance demonstration program (PDP). This drum was designed and delivered for the first performance demonstration program cycle. Illustrations are provided specifying dimensional and material attributes. Complete technical details on the design of this matrix drum are provided in the Lockheed Martin Idaho Technologies Company document, "Performance Demonstration Program for Nondestructive Assay for the TRU Waste Characterization Program, Cycle I Matrix Drum Design", (INEL-94/0274).

The zero matrix drum configuration was based on the cycle I PDP plan objectives, that is, establish baseline nondestructive waste assay system performance characteristics and provide for a means to assess system comparability. Assessment of baseline performance required a zero matrix or empty matrix drum useful for verifying fundamental calibrations.

The matrix drum configuration includes provisions to install and physically fasten a matrix in place in addition to allowing for the convenient external introduction and precise location of PDP standards within the drum volume. Figure $\mathrm{C}-1$ illustrates the zero matrix drum configuration minus the DOT $17 \mathrm{C}$ drum (UN identification code $\mathrm{UN} 1 \mathrm{~A} 2 / \mathrm{X}$ ), providing an overall perspective of the various components.

Aluminum source insert fixtures are provided for each of the three insert tube radii, Figure C-2. The PDP standard(s) is positioned at a desired vertical location in the source insert fixture through the use of small plunger rods. The insert fixture is then positioned into the source insert tube.

Matrix drums intended to simulate interfering waste forms will be based on the same general design as the zero matrix drums. In the case of waste matrix drums, the void spaces in the empty drum will be filled with appropriate quantities of simulated waste materials. These simulant materials will be matched to the actual wastes in chemical composition as closely as possible. The simulated waste will be fixed in place within the drum and distributed throughout the drum as is appropriate to the test. Insert tube matrix spacers will be provided when appropriate for use with the matrix drum to fill any void space within the source insert fixture not occupied by PDP standard(s) thus assuring a uniform matrix medium. The Program Coordinator will ensure that essential details of each drum design are communicated to PDP participants prior to its use in any PDP test.

An assembled PDP sample is shown in Figure C-3 with the tamper indicating device in place. The exterior PDP matrix drum color is dark blue. Figure $\mathrm{C}-4$ provides the outside height of the PDP matrix drum measured from the base of the bottom drum rim to the top most component of the drum, that is, the insert fixture top ring in the as-installed configuration. 


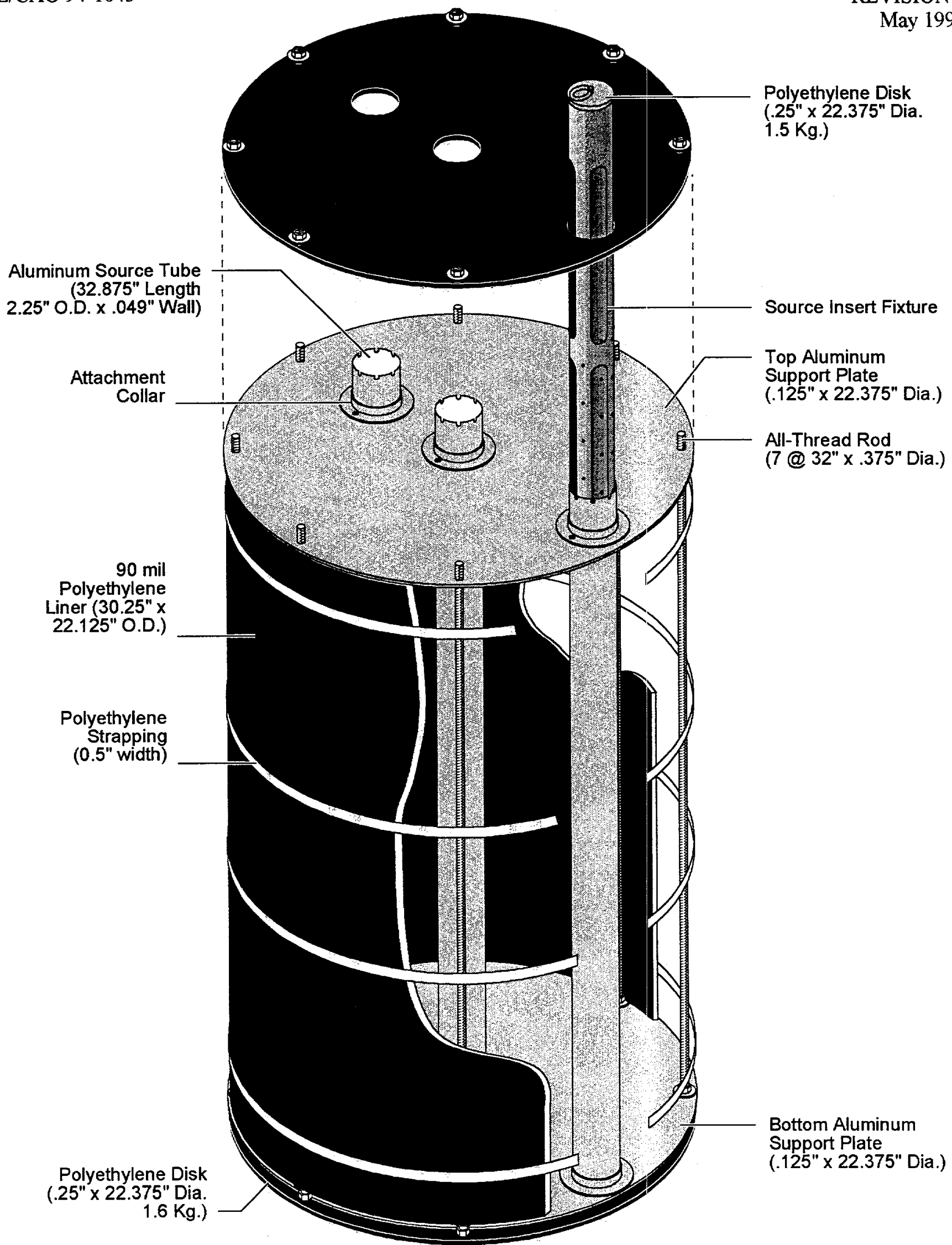

Figure C-1 PDP Zero Matrix Drum 

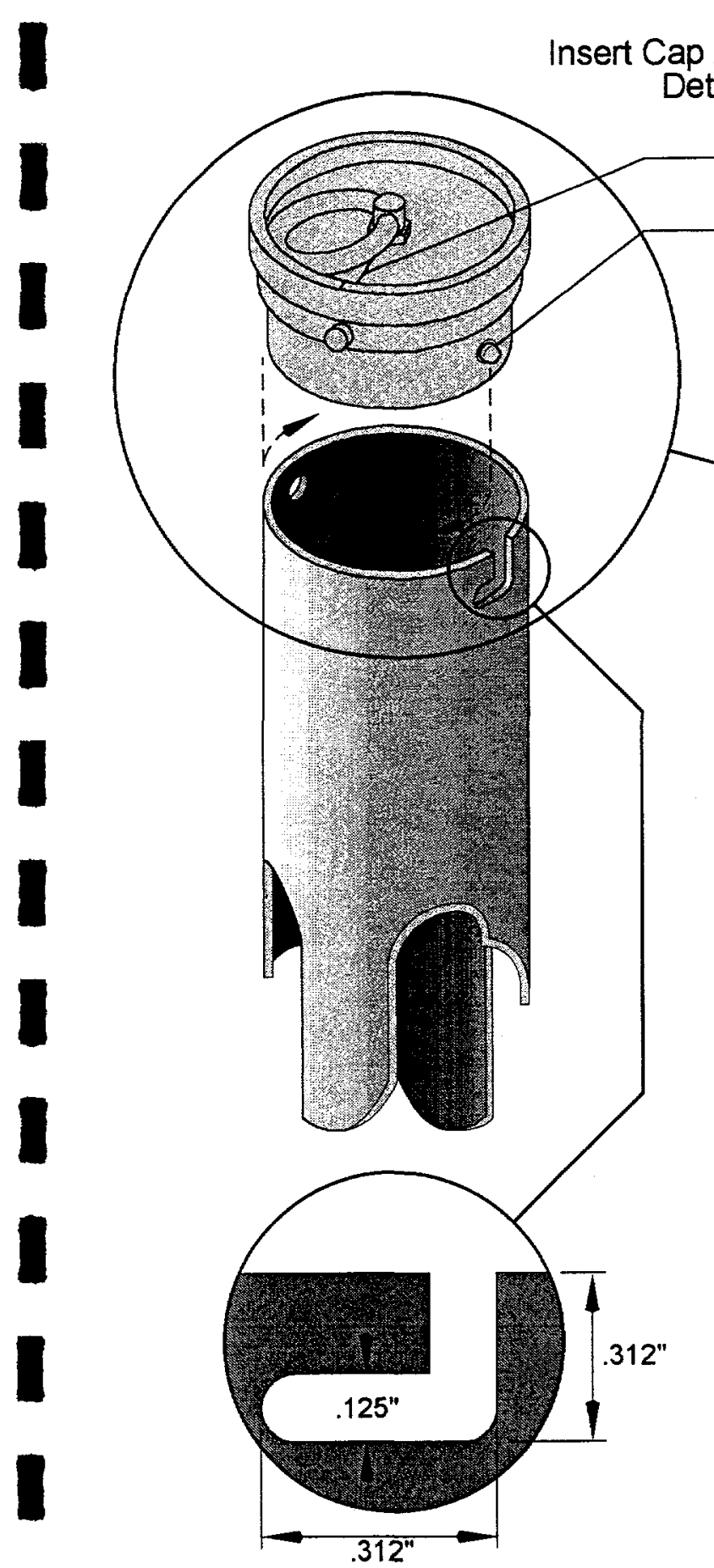
Detail Angular Demarcation Line $1 / 4^{\prime \prime}-20 \times 3 / 4 "$ SST spring plunger (lock insert cap assembly by sliding plunger into slot and turning)

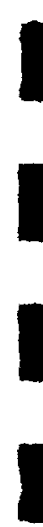

Locking Slot Detail
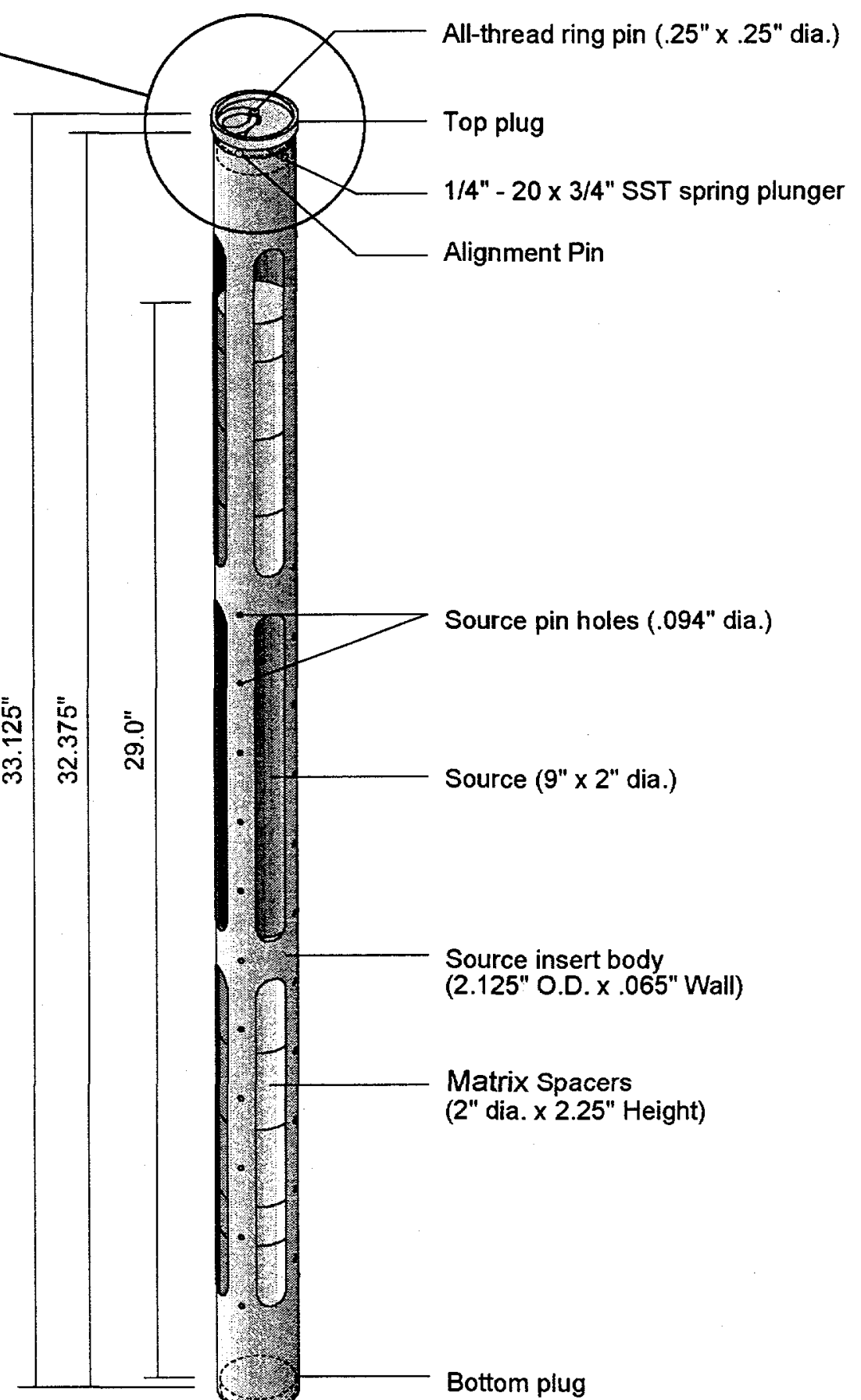
Alignment Pin

Source pin holes (.094" dia.)

Source $(9 " \times 2 "$ dia. $)$

Source insert body

(2.125" O.D. x .065" Wall)

Matrix Spacers

(2" dia. x 2.25" Height)

Figure C-2 PDP Drum Source Insert Fixture 


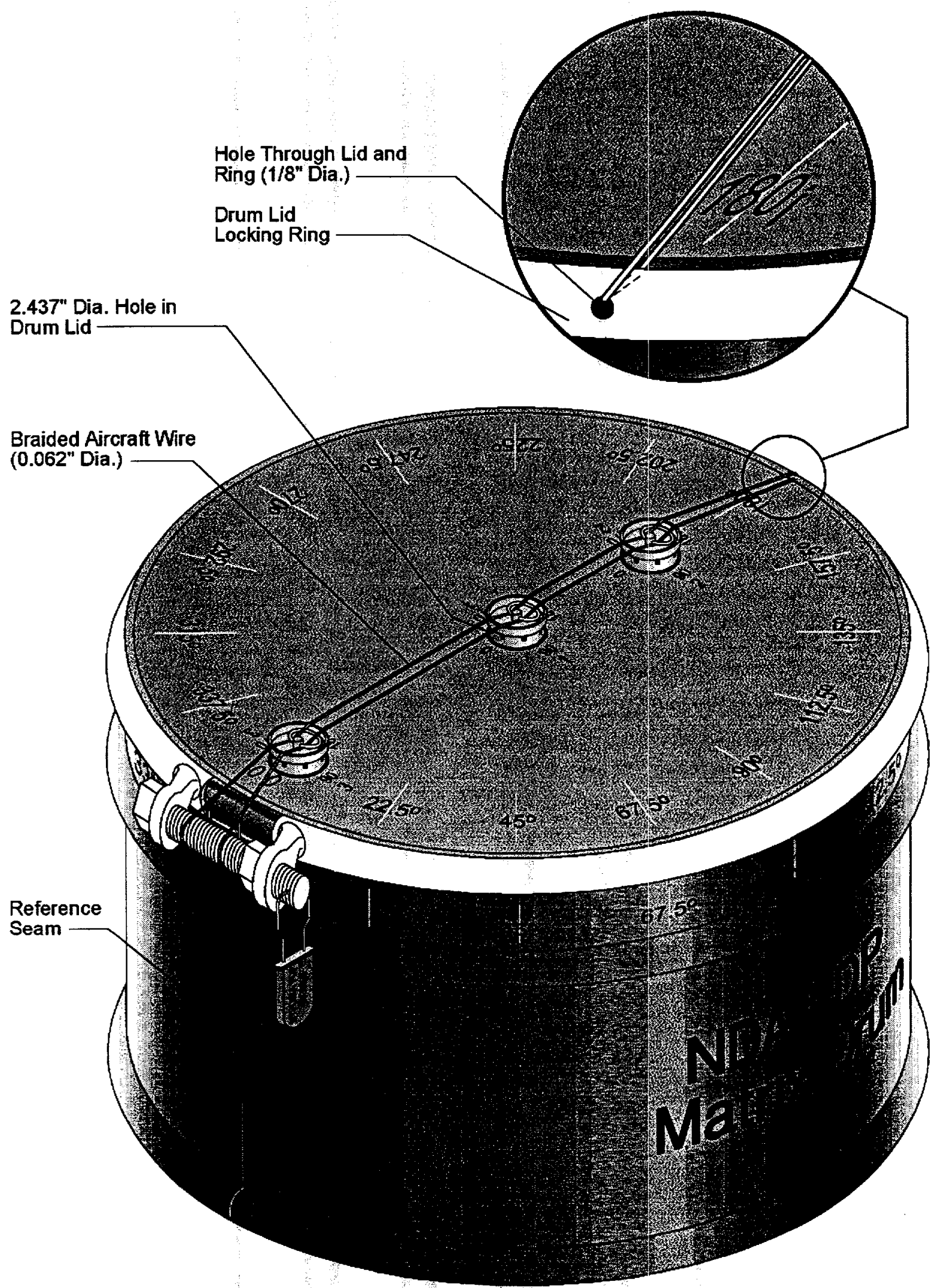

Figure C-3 Prepared PDP Sample with TID in Place 

是

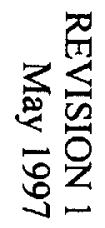




\begin{tabular}{|l|l|}
\hline Laboratory Name: & Drum Number_of_In This Cycle \\
\hline PDP Distribution (Mo/Yr): & PDP Sample ID: \\
\hline Drum Serial No.: & Comments: \\
\hline
\end{tabular}

Authorized:

\section{Technical Liaison}

\begin{tabular}{|l|l|l|l|}
\hline $\begin{array}{c}\text { PDP } \\
\text { Standard } \\
\text { Serial \# }\end{array}$ & Tube \# & \multicolumn{2}{|r|}{$\begin{array}{r}\text { Rod Position \# } \\
\text { Initial }\end{array}$} \\
\hline Source 1 & & & \\
\hline Source 2 & & & \\
\hline Source 3 & & & \\
\hline Source 4 & & & \\
\hline Source 5 & & & \\
\hline Source 6 & & & \\
\hline Source 7 & & & \\
\hline Source 8 & & & \\
\hline Source 9 & & & \\
\hline
\end{tabular}

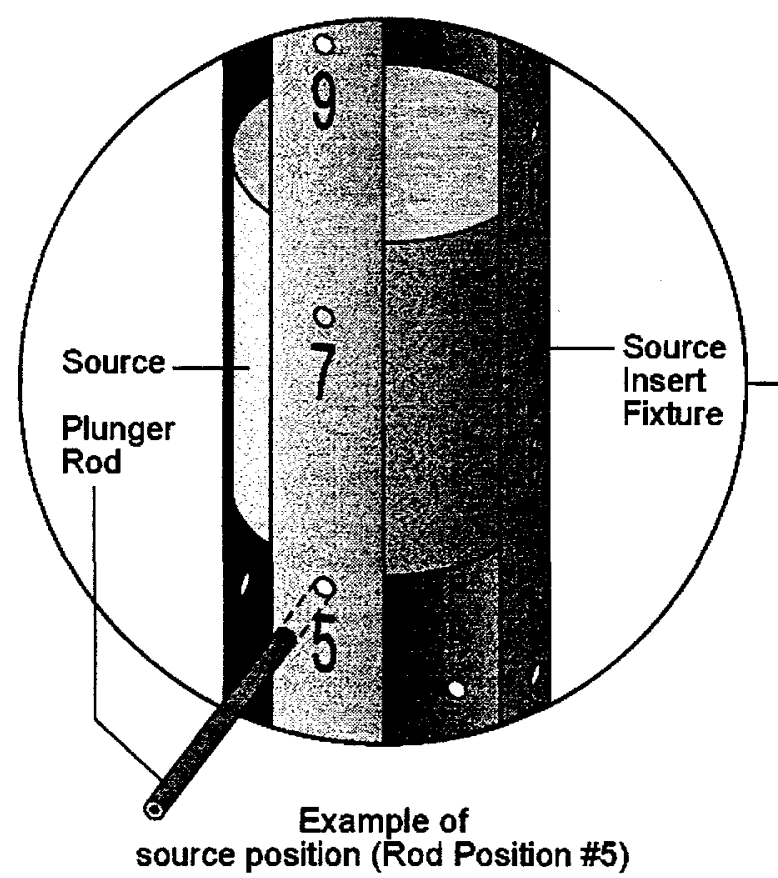

PDP Standards Custodian

\section{Date}

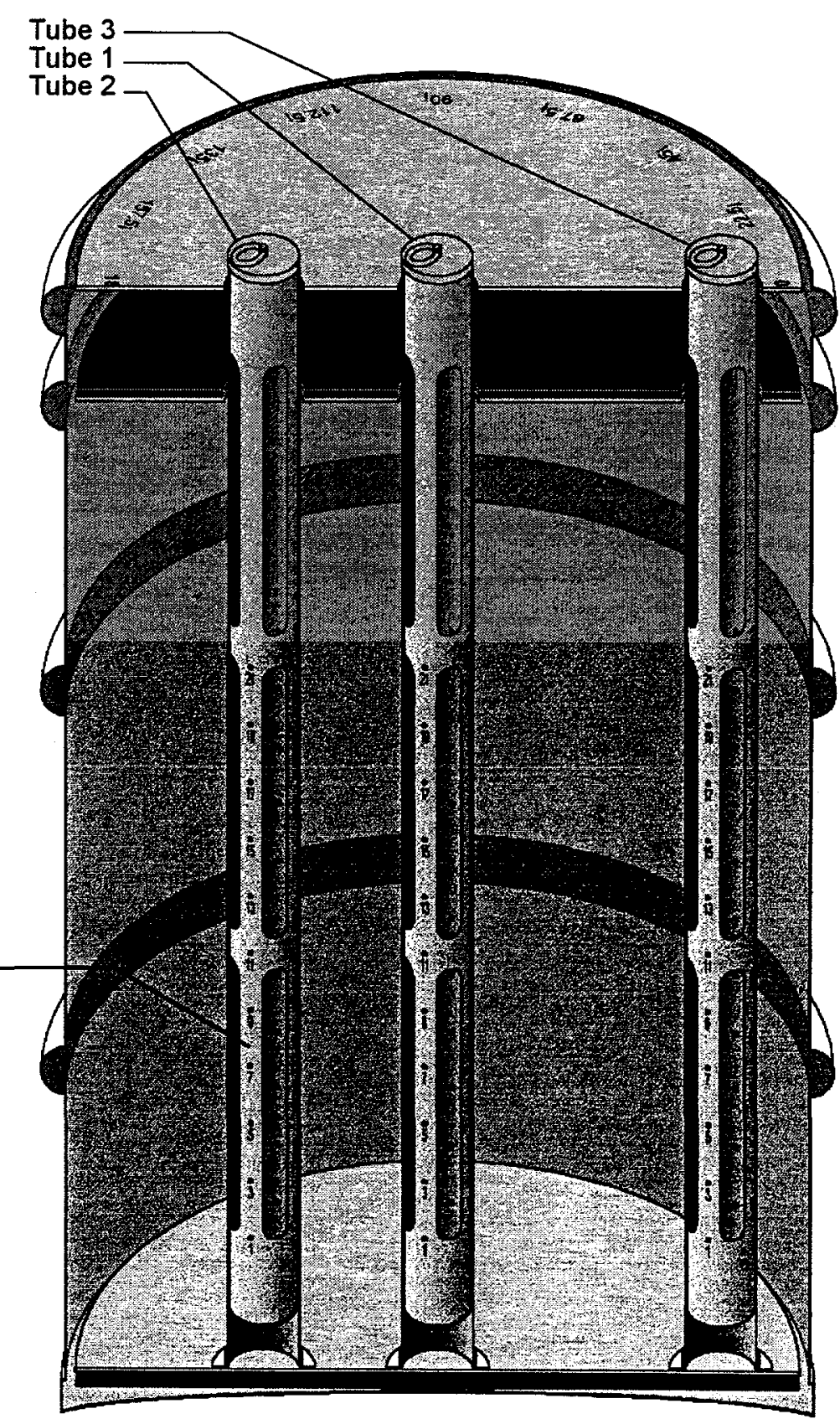




\section{PDP Sample Custody Form for Nondestruletive Assay}

Drum Serial Number :

TID Serial Number :

Distribution Cycle Number :

Comments :

\section{Sample Preparation}

\begin{tabular}{|c|c|}
\hline Sample Preparation Date: & \\
\hline PDP Standards Custodian & Date \\
\hline & Initials \\
\hline \multirow{3}{*}{\multicolumn{2}{|c|}{$\begin{array}{l}\text { Standards properly placed : } \\
\text { Matrix drum TID properly sealed : } \\
\text { Sample Information Form attached and sealed: }\end{array}$}} \\
\hline & \\
\hline & \\
\hline Standards Configuration Attestant & Date \\
\hline
\end{tabular}

\begin{tabular}{||l|l|l|l|}
\hline \hline Relinquished By: & Date/Time & Received by : & Date/Time \\
\hline \hline Standards Custodian & & Assay Coordinator & \\
\hline
\end{tabular}

[This is the VTSR. After completion to this point, return a copy to the Program Coordinator.]

\begin{tabular}{|l|l|l|l||}
\hline & & & \\
\hline & & & \\
\hline & & & \\
\hline & & & \\
\hline & & & \\
\hline & & & \\
\hline
\end{tabular}

Final Disposition By:

Date/Time

Disposition

\begin{tabular}{|l|l|l|}
\hline & & \\
\hline
\end{tabular}

White: Program Coordinator copy on final disposition

Canary: SPT copy on final disposition

Pink: Program Coordinator copy at VTSR

Gold: $\quad$ SPT copy at VTSR 


\section{PDP Sample Information Form}

Program Segment: NDA

Drum Serial Number:

Sample Matrix Used:
Distribution Cycle:

TID Serial Number:

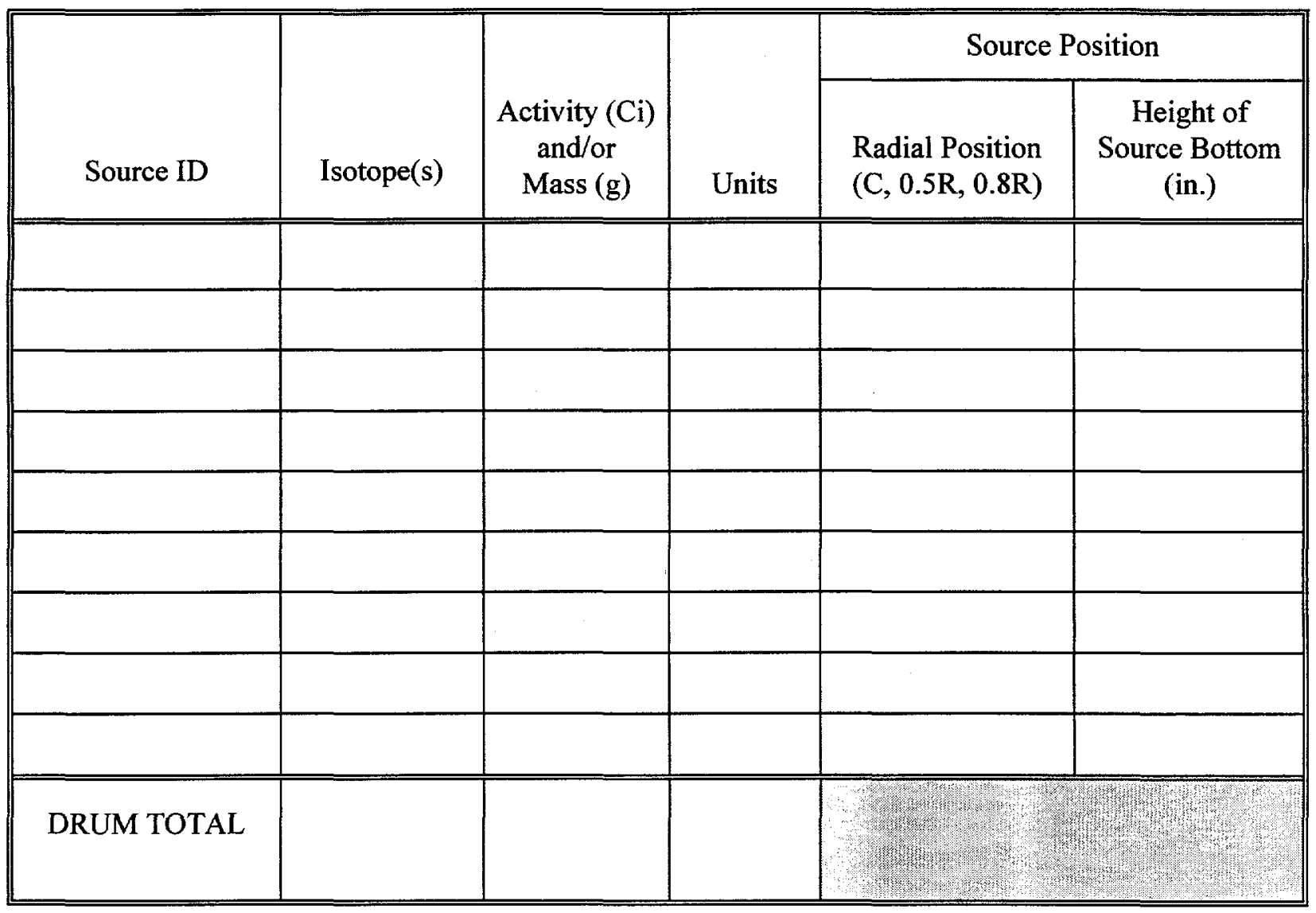

Notes: a. $\mathrm{C}=$ center tube; $0.5 \mathrm{R}=$ Tube at $1 / 2$ radius; $0.8 \mathrm{R}=$ Tube at 0.8 radius.

b. Height from bottom of support tube in inches.

Sample Preparation Team Signatures:

PDP Standards Custodian

Standards Configuration Attestant
Date

Date 


\section{PERFORMANCE DEMONSTRATION PROGRAM REPORT FORM NONDESTRUCTIVE ASSAY}

Laboratory ID: PDP Cycle: Drum Serial No.:
Assay Facility:

Supplemental Cycle:
Replicate: of

Laboratory Sample ID:

Final Result Summary

\begin{tabular}{||l|l|l||}
\hline \multicolumn{1}{|c|}{ Parameter } & Final Result & Total Uncertainty (One Standard Deviation) \\
\hline Total Pu-239 Fissile equivalent $(\mathrm{g})$ & & \\
\hline Total alpha activity (Curies) & & \\
\hline Thermal Power $(\mathrm{W})$ & & \\
\hline
\end{tabular}

\section{Method Summary}

\begin{tabular}{|l|l|l|l|l|l|l|}
\hline & & & Associated & Count Time & \multicolumn{2}{|c|}{ Analysis } \\
\cline { 6 - 7 } & Identification & Classification & SOP & Date & Time \\
\hline Method 1 & & & & & & \\
\hline Method 2 & & & & & & \\
\hline Method 3 & & & & & & \\
\hline
\end{tabular}

Individual Isotope Data

\begin{tabular}{|c|c|c|c|c|c|c|c|c|}
\hline \multirow[b]{2}{*}{ Isotope } & \multirow[b]{2}{*}{ Activity Result } & \multicolumn{2}{|c|}{ Uncertainty } & \multicolumn{4}{|c|}{ Method of Quantitation } & \multirow{2}{*}{$\begin{array}{l}\text { Method } \\
\text { Number } \\
\text { (From } \\
\text { Summary) }\end{array}$} \\
\hline & & $\overline{\text { Count }}$ & Total & Direct & Ratio & $\begin{array}{l}\text { Scaling } \\
\text { Isotope }\end{array}$ & $\begin{array}{l}\text { Ratio } \\
\text { Value } \\
\end{array}$ & \\
\hline${ }^{238} \mathrm{Pu}$ & & & & $\square$ & $\square$ & & & \\
\hline${ }^{239} \mathrm{Pu}$ & & & & $\square$ & $\square$ & & & \\
\hline${ }^{240} \mathrm{Pu}$ & & & & $\square$ & $\square$ & & & \\
\hline${ }^{241} \mathrm{Am}$ & & & & $\square$ & $\square$ & & & \\
\hline & & & & $\square$ & $\square$ & & & \\
\hline & & & & $\square$ & $\square$ & & & \\
\hline & & & & $\square$ & $\square$ & & & \\
\hline
\end{tabular}

COMMENTS:

APPROVAL: 


\section{PDP Sample Disassembly Form for Non-Destructive Assay}

Drum Serial Number:

TID Serial Number:

Distribution Cycle Number:

\section{Sample Disassembly Record}

Sample Disassembly Date:

Condition of Seals and Standards

Sample Information Form attached and sealed:

$\begin{array}{llll}\text { Yes } & \square & \text { No } & \square \\ \text { Yes } & \square & \text { No } & \square\end{array}$

Matrix drum TID properly sealed:

Standards properly placed (Crossout if Not Applicable):

$\begin{array}{llllll}\text { Source 1 } & \text { Yes } & \square & \text { No } & \square & \text { Condition: } \\ \text { Source 2 } & \text { Yes } & \square & \text { No } & \square & \text { Condition: } \\ \text { Source 3 } & \text { Yes } & \square & \text { No } & \square & \text { Condition: } \\ \text { Source 4 } & \text { Yes } & \square & \text { No } & \square & \text { Condition: } \\ \text { Source 5 } & \text { Yes } & \square & \text { No } & \square & \text { Condition: } \\ \text { Source 6 } & \text { Yes } & \square & \text { No } & \square & \text { Condition: } \\ \text { Source 7 } & \text { Yes } & \square & \text { No } & \square & \text { Condition: } \\ \text { Source 8 } & \text { Yes } & \square & \text { No } & \square & \text { Condition: } \\ \text { Source 9 } & \text { Yes } & \square & \text { No } & \square & \text { Condition: }\end{array}$

Comments:

Standards Configuration Attestant

Date

PDP Standards Custodian

Date 
